\title{
التنظيم الشكي في أسس العلاماتية لشعارات الجامعات العراقية
}

م.د. ساهرة عبد الواهد الففابيs

كلية الفنون الجميلة/ جامعة بابل الفيك

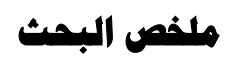

ان الثُعار وسيلة لتفسير الأفكار و الاحتياجات و هو وسيلة اتصسال بصرية لذا فانه يستخدم في كافة المجالات و هو

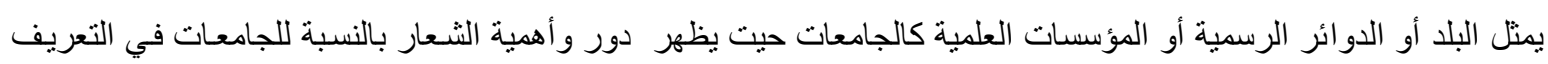

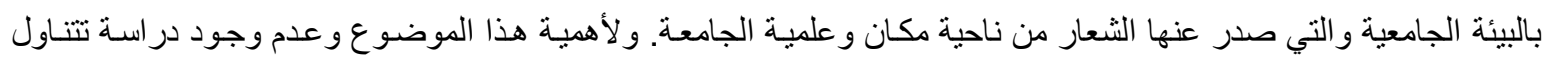

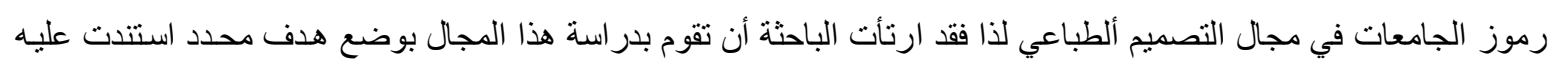

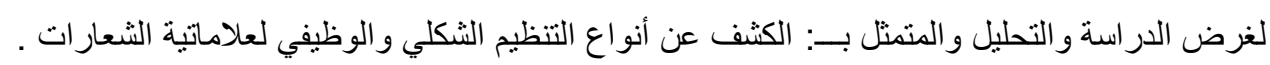

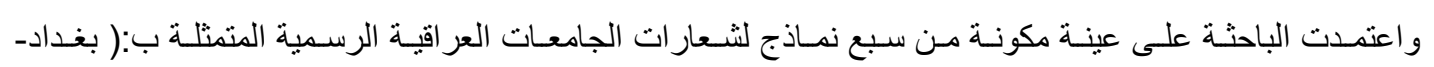

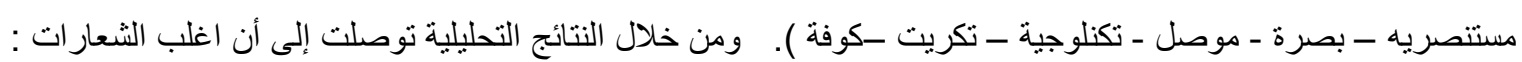

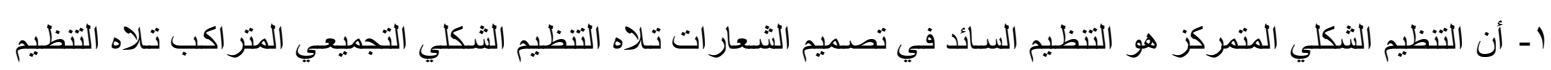

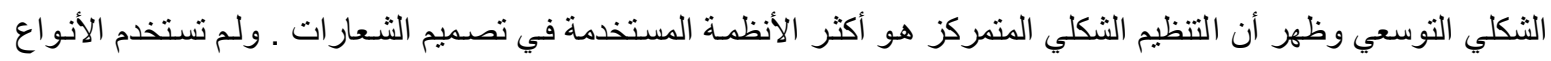
الأخرى من التنظيم .

ז- لم يحقق التنظيم الثكلي المتبع في الثعارات علاقة في أسس تصميم العلامات فقد ظهر أن (اللون و الحجم و الاتجاه والملمس)

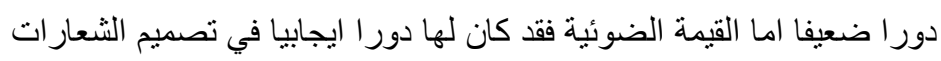

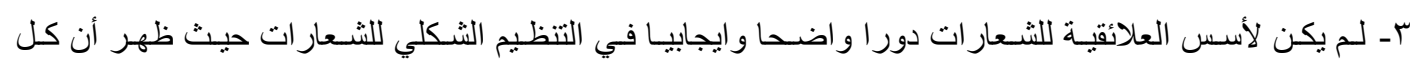

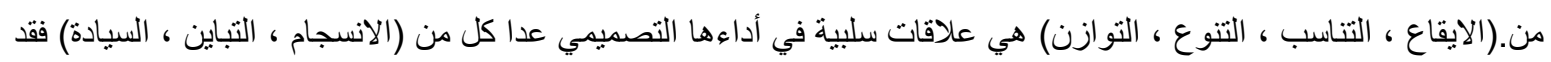

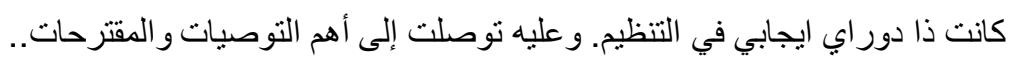

Research Summary

The logo and a way to interpret the ideas and needs, and is a means of communication visual so it is used in all areas and is representing the country or government departments, scientific institutions, such as universities saluting shows the role and importance of the logo for universities in the definition of the university environment, which was issued by the logo in terms of place and a scientific university. And the importance of this topic and the lack of a study on universities codes in the field of graphic design has therefore held that the researcher is studying this area set a specific target relied upon for the purpose of study and analysis and represented by :

1. disclose the types of formal and functional for Alamatah logos regulation.

And it adopted a researcher on a sample of seven models of the official slogans of Iraqi universities b :( Mstnasrah Baghdad - Basra - connector - Tknlogih - Tikrit -kovh ).

Through the analytical results it found that most of the slogans :

- That the formal organization based organization is prevalent in the design of logos, followed by formal regulation Synthesis overlapped, followed by formal regulation and expansion it appeared that the organization is more formal based systems used in the design of logos. Other types of regulation were not used. 
2. did not achieve formal regulation adopted in logos relationship in the foundations of design labels have appeared that (color, size, direction and texture ) role is weak either 0 photovoltaic value has had a positive role in the design of logos.

3. You do not founded Relational slogans clear and positive role in the formal organization of the slogans where it appeared that all of the . ( Rhythm , proportionality, diversity, balance ) are negative relationships in performance design except each of the ( harmony, contrast, sovereignty ) was a Dhoruai positive in regulation. And it came to the most important recomm

- : 1-

كان الاهتمام بالثعار و إخر اجه وتطويره من الناحيـة الجماليـة الشكلية والوظيفيـة بتفق مـع أهميته في حياة الإنسان العصرية ودوره البالغ الأهمية في العالم في مختلف المجالات فالثـعار هو اللغـة الحديثة للتعبير عن احتياجاتتا ورغباتتا حيث انه يظم كل أوجه النشاط التي تشمل جميع نواحي الحياة الحديثة. أن الثـعار غالبـا مـا يرمـز لـه بالبسـاطة غيـر انـهـ مـن الناحيـة الوظيفيـة والرمزيـة فهو عمبـق في

مفاهيمه وما يعنيه وهو نتاج خلاف يخرجه المصمم ويبتكره مستخدم كل ما لديـه من خيـال ومعرفة ومهارة ليسهل لنا مهمة التعبير عن حاجتنا العاطفية والروحية و المادية وفي مختلف النو احي الحياتية مستخدما أدواته البسيطة من (خط ولون وضوء) ليخرج أفكار او إبداعات ذهنية لا حصـر لها في المو اضيع الحياتيـة المختلفة. فالثـعار وسـيلة لتفسير الأفكـار والاحتياجـات ولذا فانـه يسـتخدم شـعار لكل الـدوائر الرسـمية أو المؤسسـات او الثركات وهو في الصحف والمجلات أو يعبر عن الدوائر والمؤسسـات العلميـة المهمة كالجامعات حيث أن هذه الثـعار ات تمثنل عناصـر ترمـز وتعبـر عن هـذه الجامعـات فوظيفـة الثـعار المسـخدم في الجامعـة هـو التعريف بالبيئة التي صدر منها الثعار من ناحية مكان الجامعة وعلميتها من خلال التداول في الكتب الرسـية و الإعلانات وكافة المجالات التي تساهم بها كل جامعة من هذه الجامعات. ورغم أهميـة هذا الموضوع لكن لا توجد فيه دراسة تتناول رموز الجامعات وهو موضوع يملا فر اغا في مجال التصميم ألطبـاعي كما انـه يسـاعد على إرساء قو اعد و أسس جديدة لتصميم الثعار ات. لذا فقد ارتأت الباحثة أن تقوم دراسـة هذا المجـال المتمثنل في (شعار ات الجامعات العراقية) كنظام و علاقات وتضع الباحثة مشكلة البحث على هيئة أسئلة: ا - هل هنالك تتظيم شكلي محدد في شعار ات جامعات القطر و على مـاذا أستند المصمم في توزيع المفردات التصميمية.

r- هل للتنظيم الشكلي علائقية في أسس العلاماتية من ناحية نقاط الجذب وشد بصري ، تضاد ، انسجام "- هل التظيم الثكلي يلائم دور علاماتية الثعار من ناحية وجود معنى مفهوم .

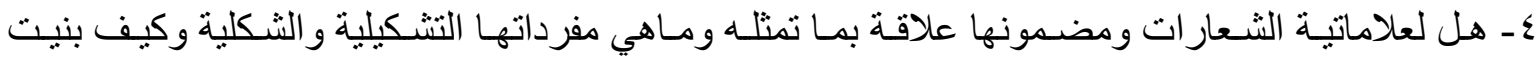
علاقاتها الأساسية ضمن تتظيمها الثكلي. ا ا أهمية البمث :- يمكن تلخيص أهمية البحث كالأتي:تسهم نتائج هذا البحث في كثف أنواع التنظيم الثكلي في الثـعارات و إبراز العلاقات المتحقة بين مفردات علاماتية الثعار ووظيفته و وضعها أمام ذوي العلاقة من متخصصين في مجال التصميم ألطباعي للإففادة منها في تطوير تتظيم الصفات المميزة للقيمة الدلالية و الجمالية في تصـاميم الثـعار ات ومـا ينسجم 
و المرحلة الحضارية والتطورات الفنية في الوقت الحاضر.

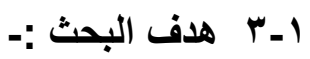

1 ـ الكثف عن أنواع التنظيم الثكلي و الوظيفي لعلاماتية الشعار ات.

1 - أـ حدود البحث

يتحدد هذا البحث بدراسة وتحليل شعار ات الجامعات العر اقية الرسمية فقط في الوقت الحسالي وتستثنى منها

الجامعات الأهلية.

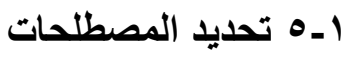

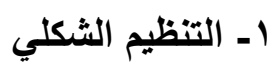

"هو علاقـات توزيع وجمع العناصـر (التشكيلات في التكوين التصميمي في بنـاء متداخل منماسلك

يساعد معه التكرار و الاستمرارية في تحقيق الوحدة). وهو البناء الهندسي الثكل . ويقول (ديكارت) أن من

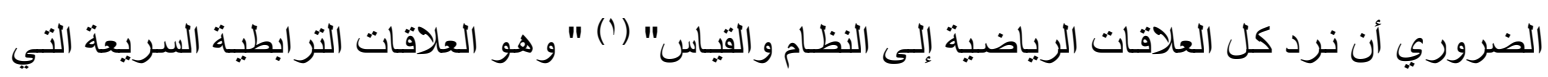
تتعزز وفق مسيرات الوحدة بموجب فعل النظام الذي يتجسد بفعل قدرته على التكامل و التلاحم " (؟). أو "هو ذللك النـاتج مـن دخول شكل على شـل بالارتبـاط بالتمـاس بالتفاعل بالتجـاور بـالاقتر اب بالابتعـاد بالتحديـ

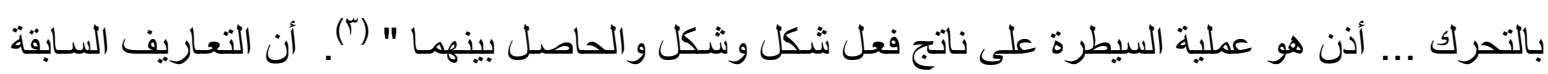
وحدها وبمفردها لا تفي بتعريف التنظيم الثكلي بالنسبة للبحث الحالي . - التعريف الإجرائي: هو نظام علاقاتي يحقق الترابطو التجانس من خلال النظام بين المفردات بعضـها مـع بعض بعلاقات

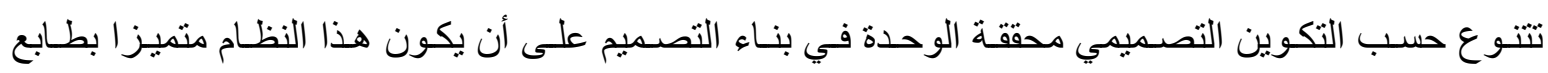
متحرك و غير تابت لكي نصل إلى حالة التغيير حتى تتولد صور ا جديدة للنظام أو بناء نظام جديد. r - أسس علاماتية الثعار " العلاماتية: هي لفظة متداولة حاليا للإشثارة إلى نظرية العلامات أو إلى أنظمـة العلامـات بشكل عام

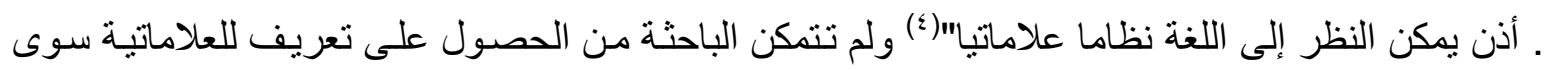

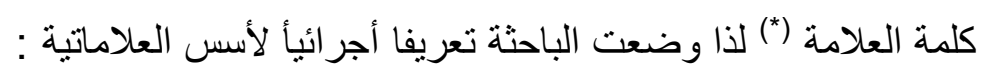

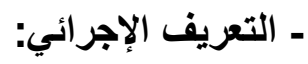

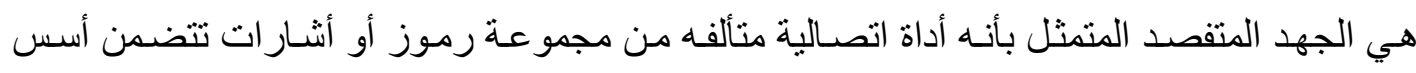

الدال و المدلول و القصد تهدف إلى مخاطبة ذهنية المشاهد باعتبار ها وسيلة اتصال فتؤثر به ويتأثر بها. r- الإطار النظري:- يتضمن الإطار النظري للبحث - ما يلى :

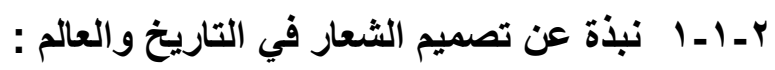

أن الإنسان هذا الكائن الأجتماعي الذي كان ومـاز ال يقوم بمحاو لاتـه من أجل يكتشف وسـائل اتصـال مختلفة ليتمكن من التفاهم بينه وبين مجتمعه و على الرغم من أن محاو لاته السـابقة هي بسبطة وبدائية إلا أنها تطورت حتى وصلت إلى ما هي عليه ألان. وقد تمثلت المحاو لات الأولى بالحركات الإيمائية بالجسد و اليد أو ملامح الوجه ثم تلت بعد ذلك مرحلة الرسم و التخطيط على جدران الكهوف حيث كانت الجماعات البشرية 
قبل اكتثاف الكتابة بمطابقة دوال العلامات وما تشير اليه أي بين الاسم والثيء حيث كانو ا يرسمون صورا و اشكالأ للحيو انات على الصخور فيعتقد أنه أنتج حيو انـا حقيقيا....ومن المحاو لات عند قدماء المصريين هي القيام بحرق أسماء الأعداء أعتقادأ منهم بأنهم سيحترقون بـاحتر اق أسمائهم (0) و قد شـاركهم في هذا الاعتقاد (البابليون) حيث كانو ا يعتبرون أن أسم أي شيء يشاركه في طبيعته الأساسية ، كما يتضح في عبارة "لم أمت

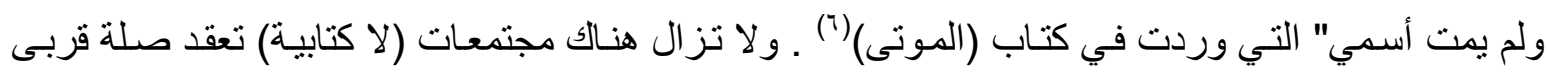

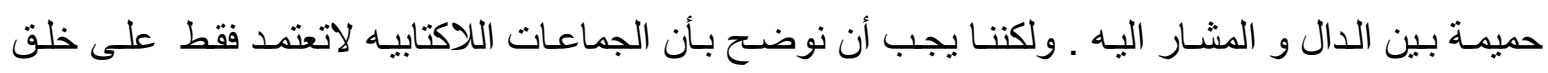

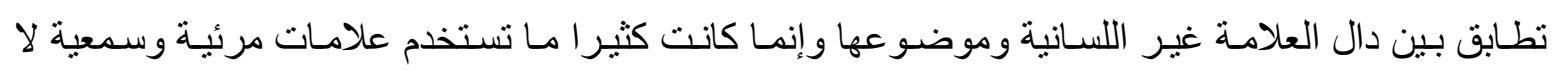

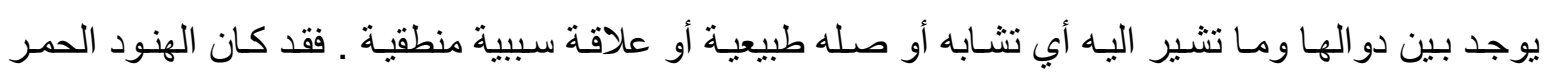
يملكون نظاما كاملا للعلامـات و كانت هذه العلامـات تمثنل لغـة معروفة تميز كل قيبلة من القبائل الاخرى ، وقد كانت النار و الاخان من أكثر العلامات أستخدامأ في عملية الاتصال حيث أن عدد السحب الدخانيه ومداها وتتابعها يمثل نوعا من التنبيه أو التحذير للقبائل الأخرى و التي تفسر مـا تقصده كإعلان عن وصـول الغربـاء

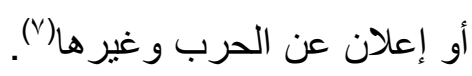

و هكذا نستطيع أن نستنتج من ذلك أن هذه المحاو لات الأولى لطرق الاتصـال والتي تطورت فيما بعد

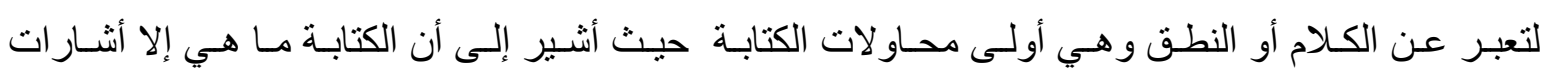

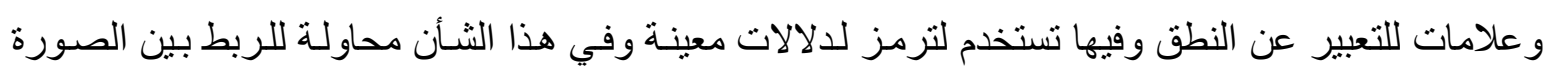
و المعنى ومثنال ذلك الكتابـة الهيرو غليفية و التي كانت عبـارة عن رموز و إثـار ات تعبر عن معسان ودلالات

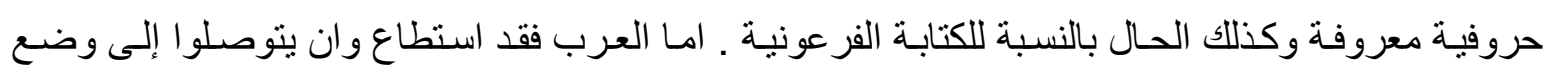
نظرية مستقلة وشاملة يمكن اعتبار ها من أكمل النظريات التي سبقت الأبحاث المعاصرة في علم الدلالة وقد توسعت دراسـة النحو بين العرب توسعا كبير ا حتى خرجت مباحثهم عن حدود تعيين العلاقة بين الألفاظ

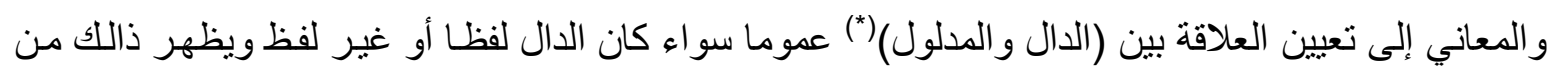

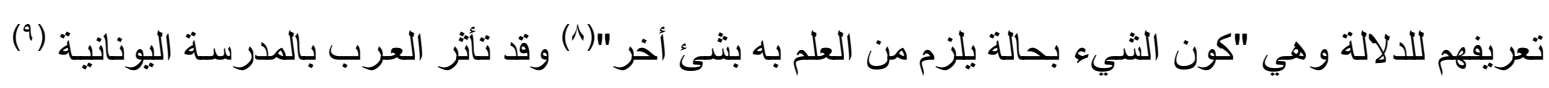

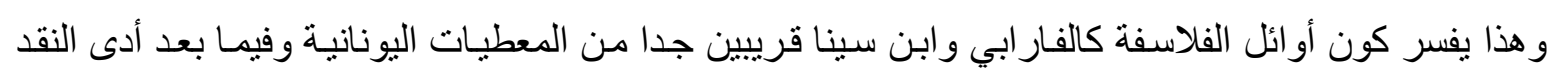
المتو اصل الذي أخضعت له المفاهيم القليلة التي وضعها هؤلاء إلى تفاصيل دقيقة في تعريف الدلالة وبوجـه عام ينحصر علم الدلالة عندهم على الدلالة اللفظية وتعريفهم لها يتبع مفهوم أرسطو ويقترب منـه فهي بنظر هم تتنـاول اللفظـة والأثر النفسي أي مـا يسمى أيضـا بالصورة الذهنيـة والأمر الخـارجي ــ ويأتي رأي ابن سينا دليلا على تقدم العرب ضمن هذا المجال و الذي كان مخالفا لأرسطو عندما توصل إلى أن دور الألفاظ ليس ضروريا فيمكن أن تكون لها أيضـا دلالة على الآثار بـلا توسط حتى يجعل لكل اثر في النفس كتابـة ـ مثنلا للحركة كتابة و السكون كتابة والسماء كتابة وأرض أخرى وكذلك كل شي .

قسمَ العرب الدلالات إلى ثلاثاً (العقلية والطبيعية والوضعية) ويأتي تقسيم الفيلسوف الأمريكي بيرس

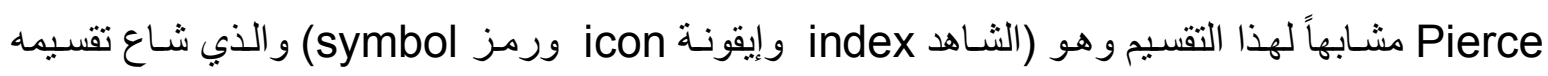
فيما بعد في السيمياء الحديثة (·.). 
ـ - تأسيس العلاماتية

لقد أقترن ظهور علم العلامـة بمعنى التأسيس المنهجي بمنبعين اثنين: الفيلسوف الأمريكي ( تشـارلز

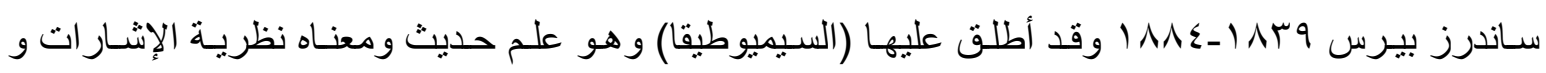

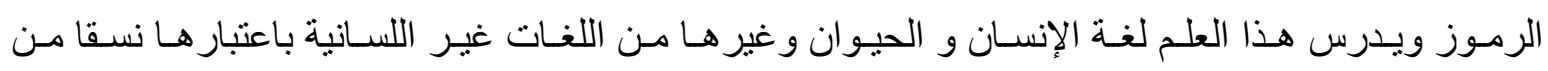

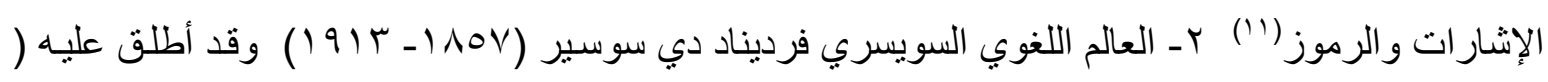
السيميولوجيا) (r') . حيث أعتبر ما جاء به (بيريس و سوسير) امر أ مسلما به.

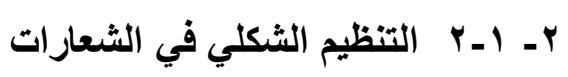
أن استنباط نظام للتصميم و إيصال معانيه هو عام لكل الفترات حيث أنه متنوع عن زمن إلى أخر غير أن المبادئ المتضمنة و قيمتها للمصمم تبقى نفسها على أن يكون النظام ذا قدره على التغيير و التجديد أذا هو إبداع و كما أن هذه المبادئ ترتبط بعلاقات تربط الأجزاء مع يعضها فتكون النظام الأساسي المستقر نظام بصورة جديدة

$$
\text { [ نظام أساسي مستقر] ] حالة }
$$

النظام

\section{تغيير}

وتفسر وحدة وتنوع الأشكال و الوحدات في الثعار ات من خـلال ذلك حيث تستقر علاقات معينه و

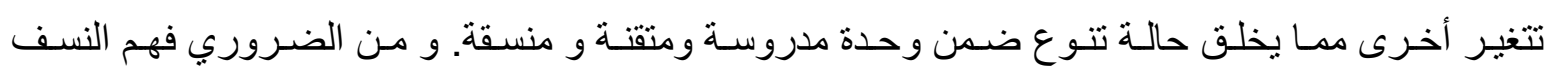

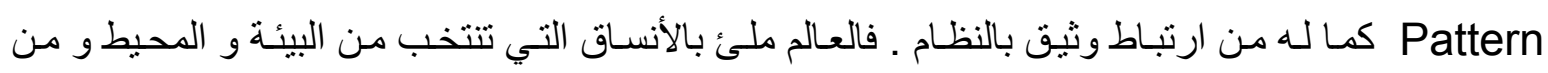

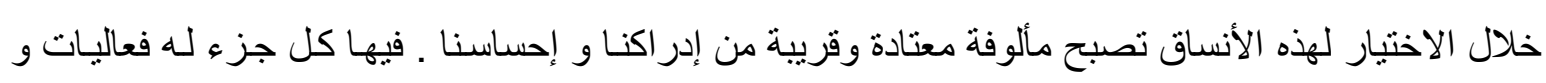

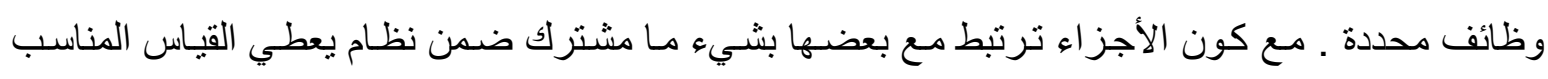

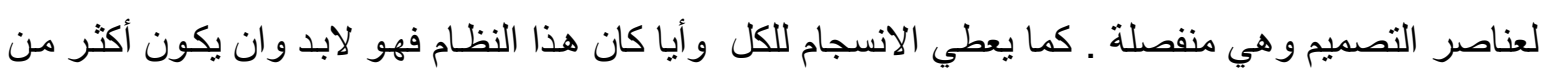
مجرد جمع خارجي لأجزائه لأنة قد يكون عبارة عن هيئات وليس عناصر فقط وهنا تحتل فكره العلاقة أهميـة

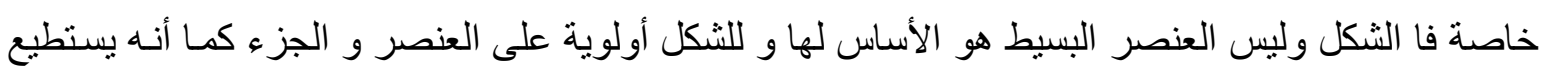

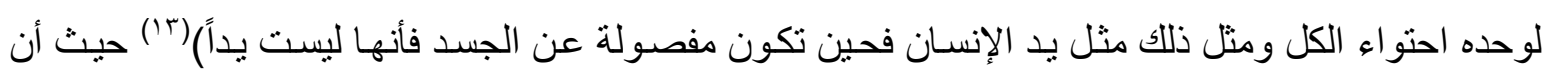
الجزء في كل . و هو شيء مختلف عن الجزء منعز لا أو مندمجا في كل أخر بفضل الخصسائص و العلاقات التي اكتسبها من موقعه و من وظيفته في حالته أي بمعنى أن النظام في التصميم يرتبط بالعلاقات و الياتها وأن

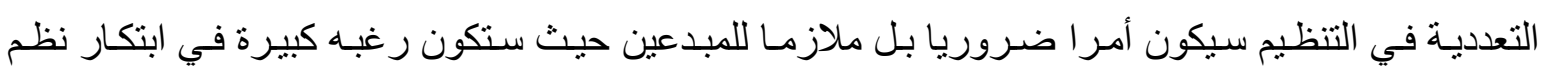
و آليات لعلاقات جديدة مضافة ليتحقق في النهاية تصميم جديد مبتكر وذلك هو الهدف الموجب في النظام (؛ُ). ولكن قد يكون لدينا زحمة في هذه العلاقات وهنا تكمن قدرة المصمم على إن يجعلها متتوعة موحدة ومثيرة في الصفات و الأداءو الأهداف ضمن النظام أو النظم التي استخدمت لتحقيق الإظهار السطحي أو ألحجمي

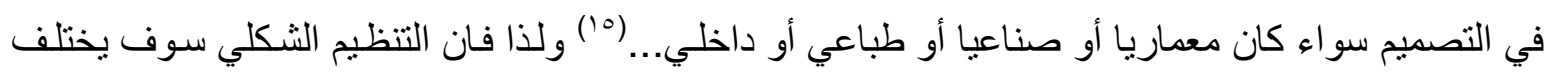
بين مصمم وآخر و يتوقف هذا التتظيم على الأهميـة التـي نعطيها لأبـراز معسالم الرؤيسة واستقرار التسلسل

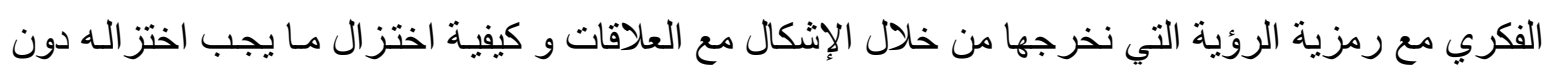
الإفر اط بالحذف أو التأكيد على مـا يجب التأكيد عليه و ذلك لأهمية الموضو عية دون العبث أو الركاكة (17) 
مع مر اعات تحقيق الوحدة والتوازن بين العناصر أو الأجزاء المكونـة للكل الواحد وبالتأكيد سيكون تأثثير كل عنصر من العناصر مجتمعا ليكون التأثير الكلي للنكل الموحد بالإضـافة إلى التنوع حيث إن الوحدة بدون تحقيق التنوع يقود إلى الرتابـة وهاتان العلاقتان همـا من الأسس الأساسية لتصميم و ليس القصد من ربط ليط

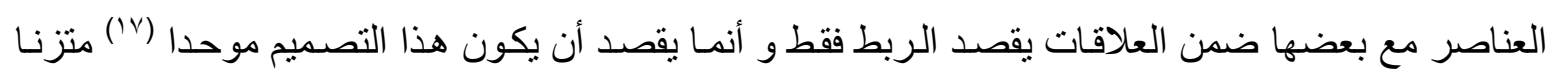
وكذلك يصبح ذا خاصية مؤثرة (^)' وهكذا تتداخل عناصر كثثرة عن طريق علاقات التوزيع و الجمع لهذه العناصر المتمثلة بطريقة التنظيم لكي تصنع على أيدينا التعقيد الثديد الذي يكتنف عملية ظهور الأشكال إلى ونى الوجود من خلال تنظيم هذه العلاقات (19). التنظيمات الشكلية : هنـاك أنواع من العلاقات التي تحقق ترابطا بين العناصر من اجل تحقيق سمة التكامل للهيئات و الأشكال وكذاللك التحام العناصر بعضها بالبعض (·r) فتتميز هذه الأشكال بقدرتها على النمو و الاندماج ومن لتصن

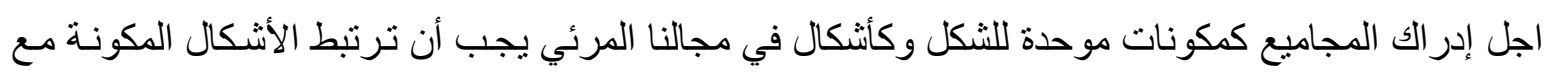

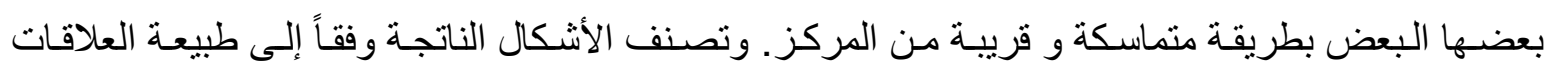

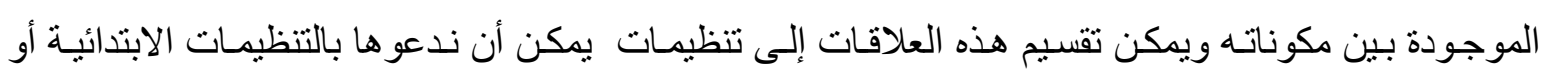
أساسيات التنظيم وندرج بعضا منها:-

\section{Type Certral التنظيم المركزي. A}

Type Linenr التنظيم الخطيم. B Type Clustered التنظيم العنقودي C

Type Grid التنظيم الثبكي D. D. D. D. D.

(r) Type Radial التنظيم الشعائي e

و هناك نظم ومعادلات تستخدم في التعامل مع المسطحات و المجسمات وفضـاءاتها تتميز بـالتنوع للوصول إلى الهـف أو الأهداف للحصول على الوظائفيـة المطلوبـة(r) وترى الباحثة إن هنـاك العديد من الأسـاليب و التقنيات و النظم التي يتعامل بها المصمح لتحقيق هدفه كما سبق توضيحه فان النظام هو متنوع من زمن إلى لى

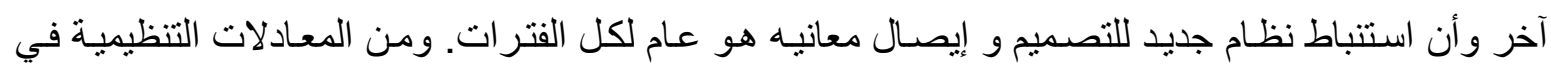

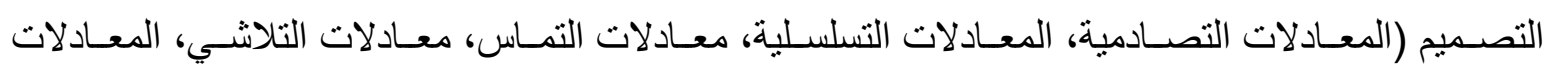
التوسعية، معادلات المحور، معادلات النسبية، معادلات التركيب، معدلات التكرار، معادلات التمركز (r؟ب)... وفيما يلي شرحا موجزا للتنظيمات الابتدائية في التصميم:

: Central type التنظيم المركزي -A و المقصود به التنظيم المتمركز حول ذاتـه و المتألف من عدد من الأشكال الثانويـة المتمركزة حول الأشكال المركزية الأصلية السـائدة(؟) وهذا التنظيم عبارة عن مركب مستقر وهو متمركز حول ذاته حيث يتألف من مجموعة من الفضـاءات الثانويـة التي تلتف حول مركزه ويكون الفضـاء المركزي الموحد للتنظيم عموما منتظما في شكله وهو كبير بما يكفي لتجميع الفضاءات و العناصر الثانوية المرتبطة كثكله و بالإمكان 
أن تكون العناصـر الثانويـة لهذا التنظيم مكافئة لبعضـها البعض في الوظيفـة وفي الثـكل و الحجم حيث إنها تستطيع أن تكون شكلاً منتظماً ومتناسقاً في محورين أو أكثر ، ومن الأمثلة على هذا النوع الأنماط الدائريـة وأنو اعها الإشعاعية والمغزلية و الحلقية. شكل رقم (1) .
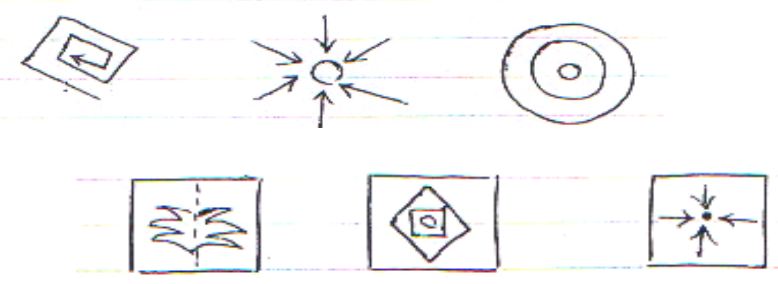

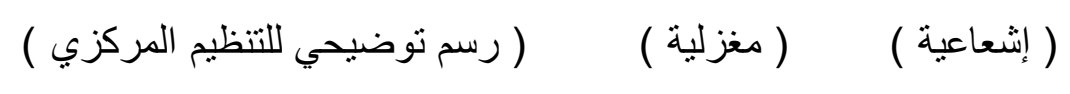

$$
\text { شكل رقم ( (1) (الأنماط الدائرية - تنظيم متمركز حول ذاته) }
$$

\section{: Liner Type التظيم الخطي -B}

وتظهر التشكيلات في هذا النمط منوزعة على هيئة خط مستمر أو متقطع أو مستقيم(ro) وقد

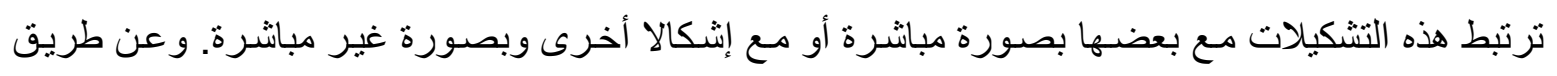
هذه التنظيمات نستطيع أن نشعر بالاتجاهية والاستمر ارية و الحركة و الاستطالة ويمكن وقف هذه التهات الاستطالة

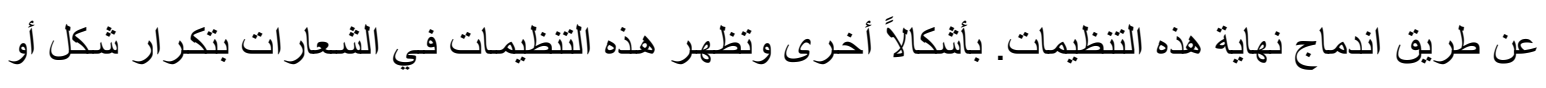
مفردة مرتين أو ثلاثة بتردد متداخل.

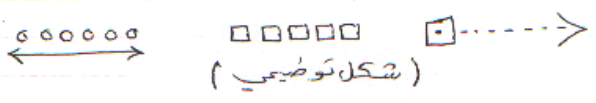

\section{:Radial type التظيم ألشعاعي -C}

وتجتهـع فيـه التشـكيلات حـول ذاتهـا مركزيـا ويمتـد عدد مـن الأذرع الخطيـة بطريقـة شـعاعيه فيهـا (ويجمع هذا النمط المركزي و الطولي حيث يضمن شكلا مهيمنا تتنج منه تنظيمات طولية أو خطية تمتـد بطريقة شعاعيه (Tr) ويكون التنظيم ألثـعاعي عبارة عن تنظيم منبسط نحو الخـارج يصل إلى محيطه ويمتد من خلال اذرعه الخطية حتى يرتبط بالعناصر الأخرى أو خو اص موقعه.

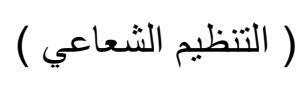

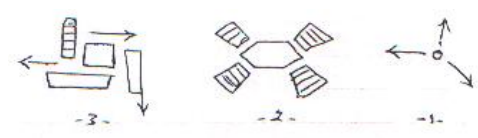

: التظظيم التجميعي D

وتتجمع فيه التشكيلات بشكل منر ابطو متتاسق أو محوري ولكنه توزيع غير هندسي ـ وتجتمع هذه

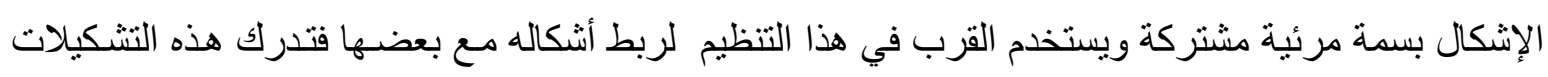

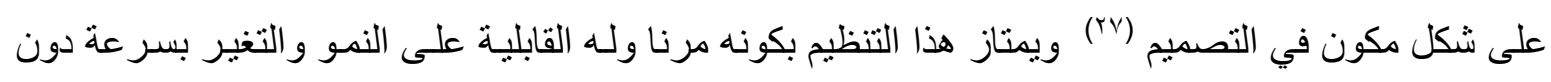
التأثير على الطابع المميز له. ( التنظيم التجميعي)

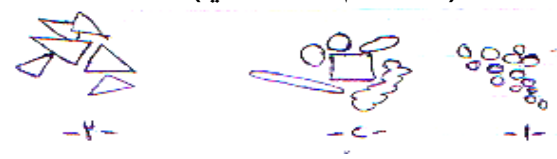




\section{e- eتنيم الثبكي Grid type:}

وبالإمكان تعريف الثبكة بأنها مجمو عتين متقاطعتين من الخطوط وتوزع التثكيلات على نظام

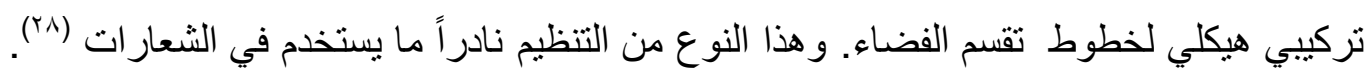

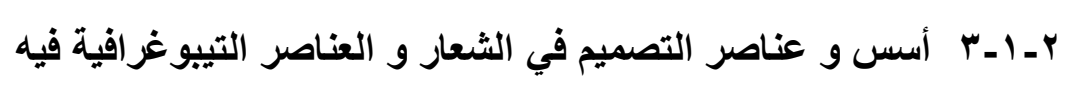

\section{: Design Elements عناصر التصميم}

أن الفنون المرئيسة مجتمعـة تتكون من اتحساد عناصر التصميم المتمثلة بـالخط والاتجـاه و الثكل و

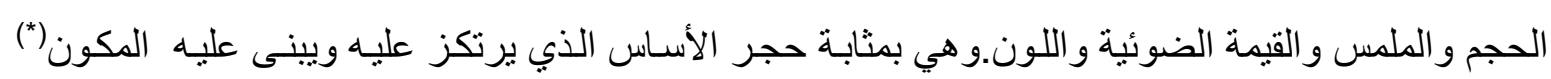

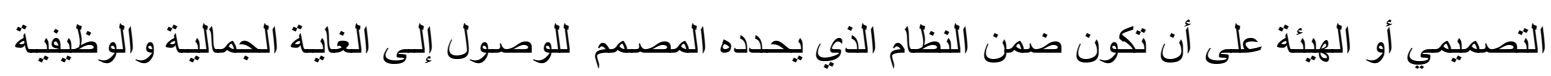

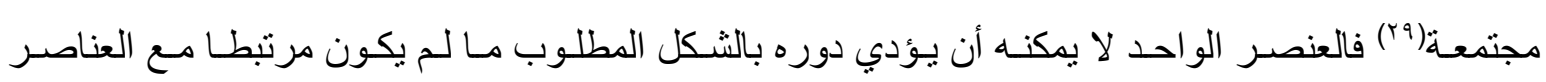

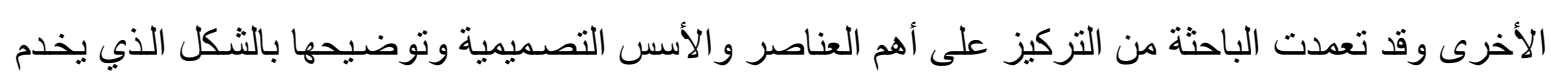

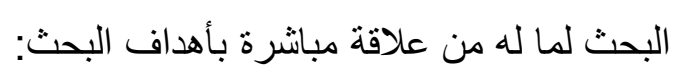

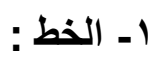

بعتبر الخط من أقدم الوسائل الفنية التي عرفت في التاريخ و التي امتازت بالمرونـة والبساطة (·•)

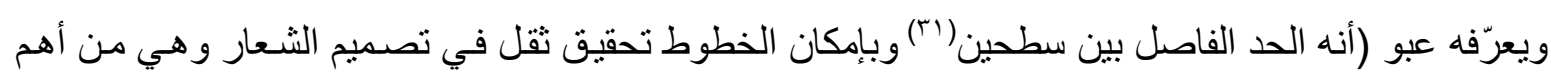

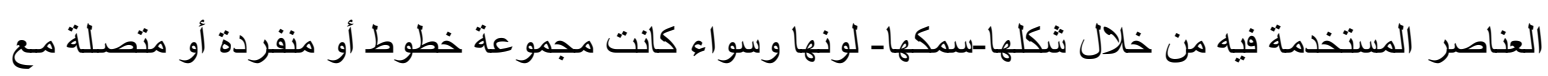

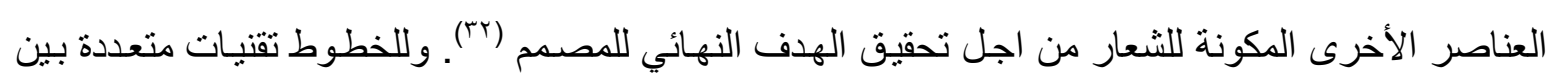

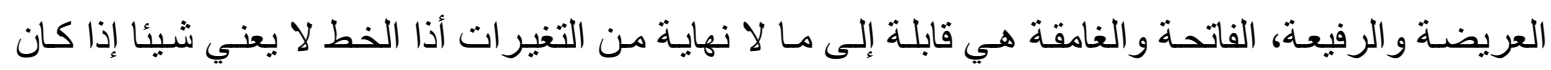

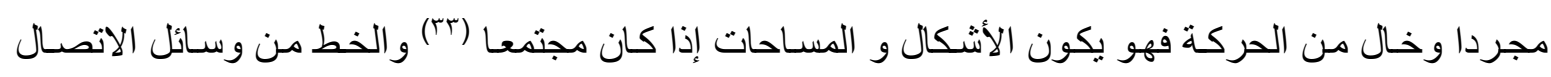

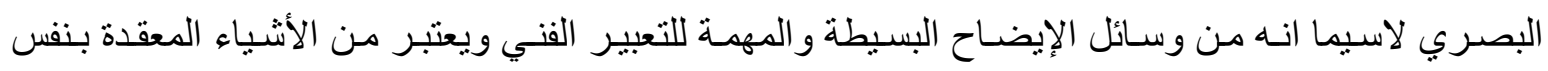

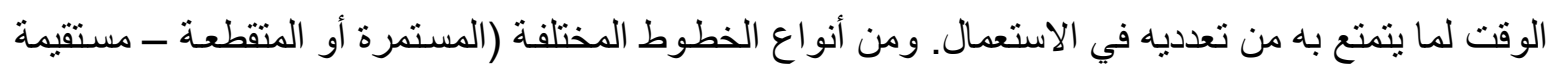

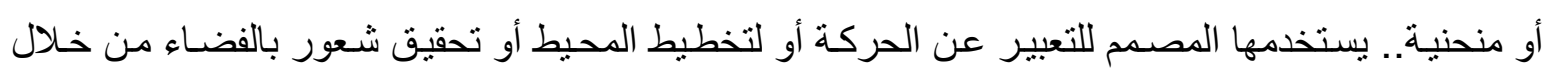

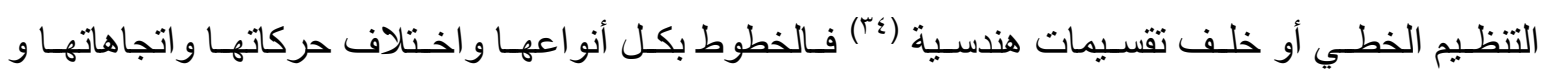

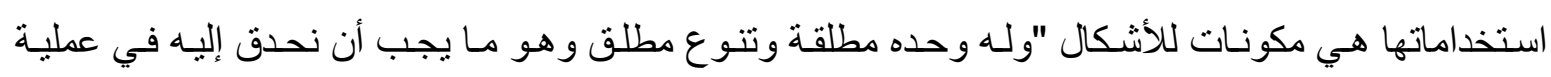
التصميم في الثعارات" (ب0).

: Direction 2 - الاتجاه

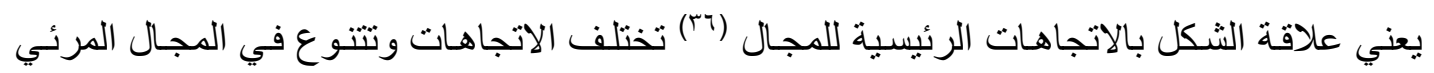

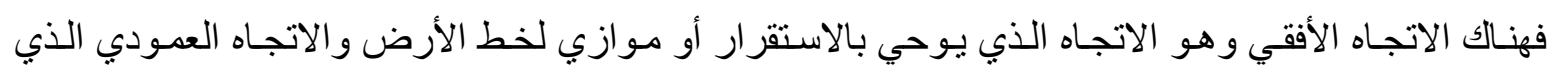

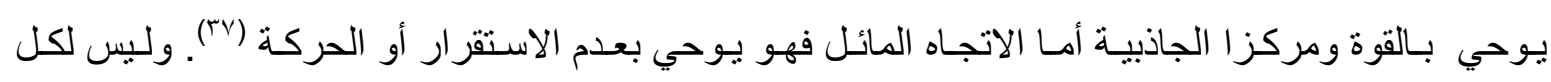

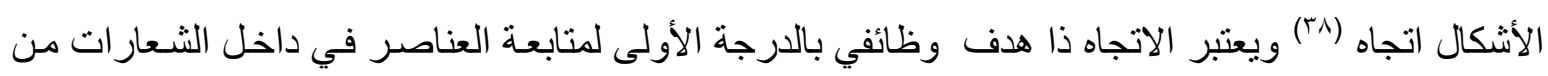

خلال اجتذاب النظر و الانتباه إلى مركز السيادة فيها. 


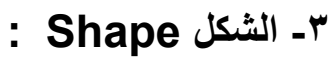

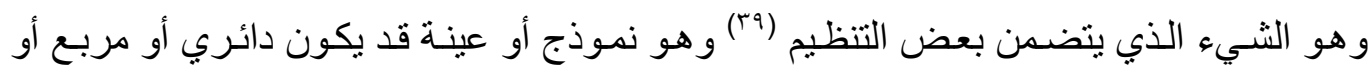

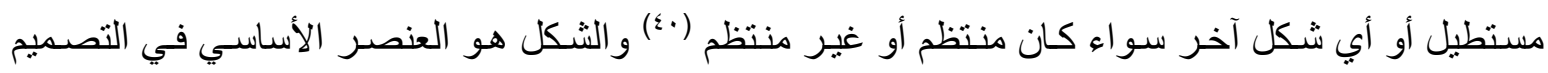
حيث يعتبر التصميم الأثكال الهختلفة و الهتنوعة في الثكل و الحجم واللون والقيمة الضوئية وللثكل علاقة

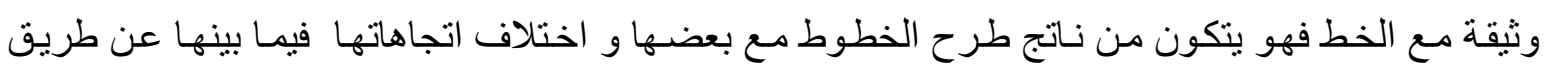
علاقات تكوينية تبدأ مجردة ثم تتطور لنكون علاقة جديدة تنساب لصباغة الهيئة بمساعدة العناصر الأخرى

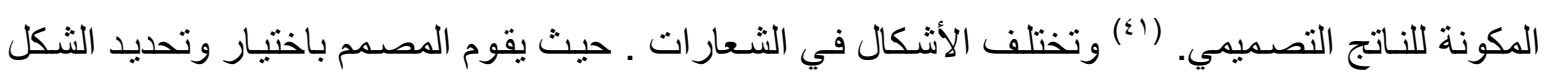

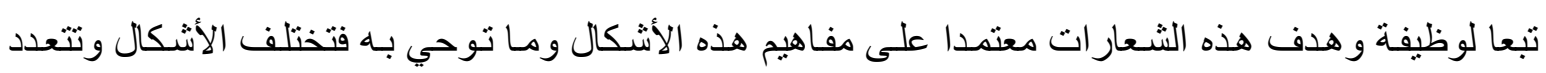

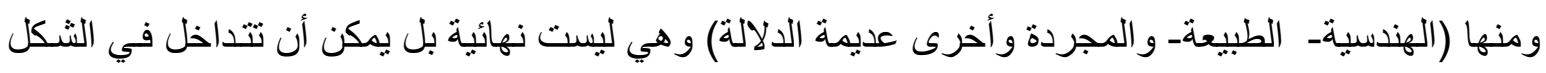

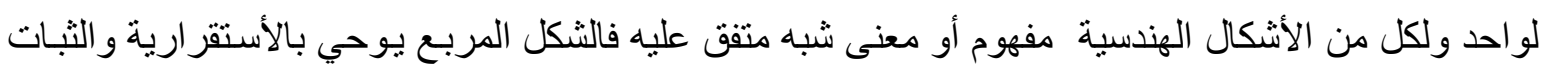

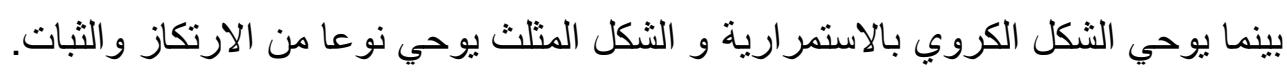

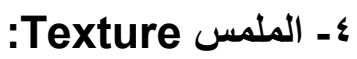

ويمكن تعريفه على انه العلاقة المتبادلة بين أحساسين المرئي و اللمسي أي انه ملمس السطوح كمـا

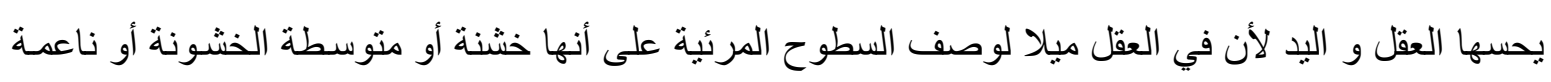

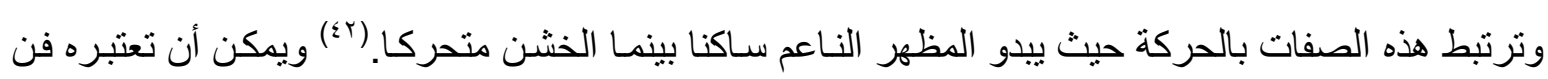

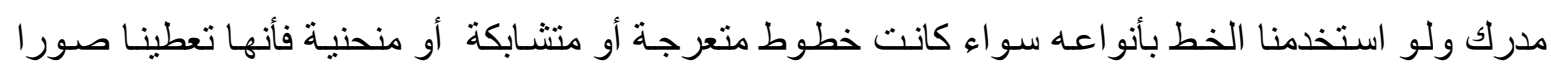

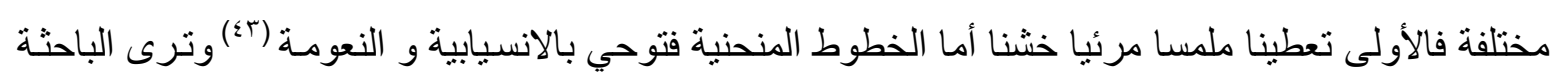

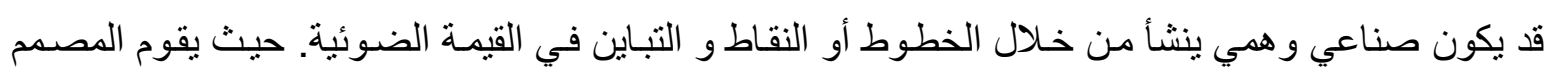

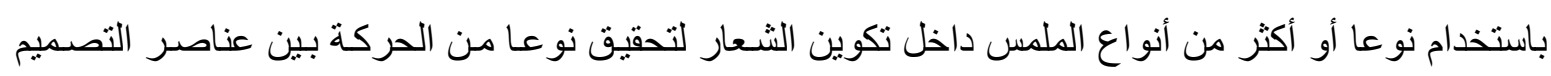
في الثعارات.

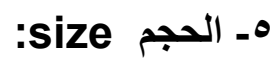

يعتبر الحجم دائما شيْ نسبي حيث غالبا ما نقوم بمقارنـة الأحجام سواء كانت صغيرة ام كبيرة تبعا

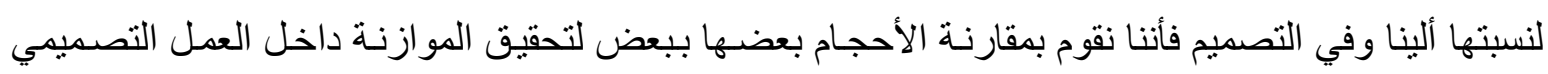

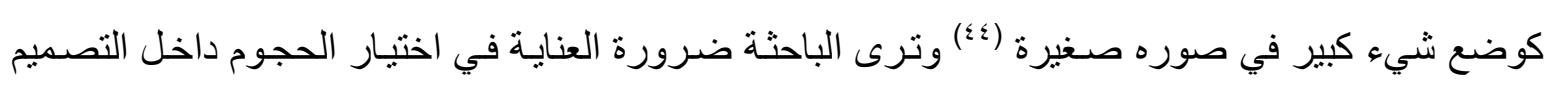

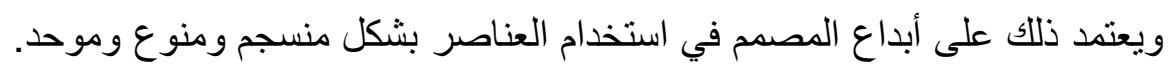

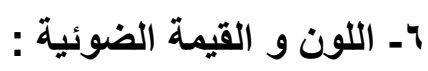

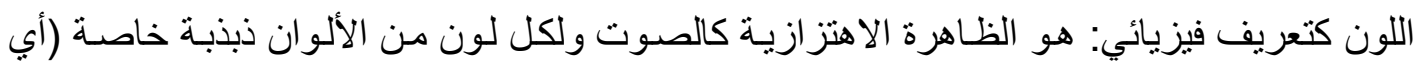

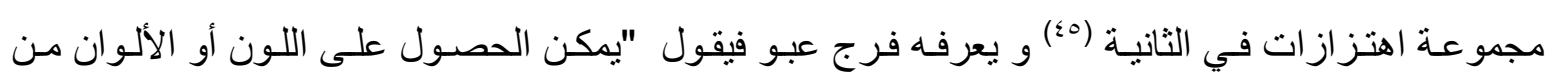

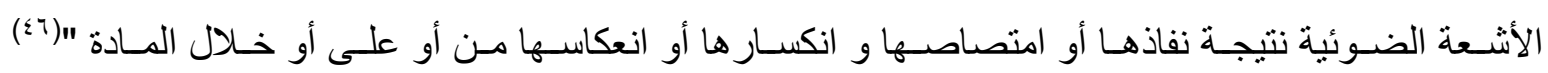

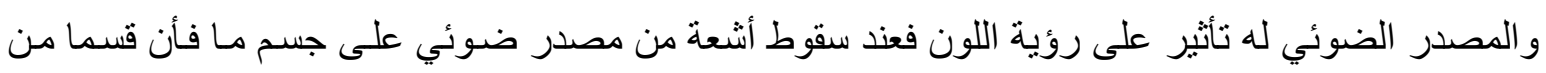

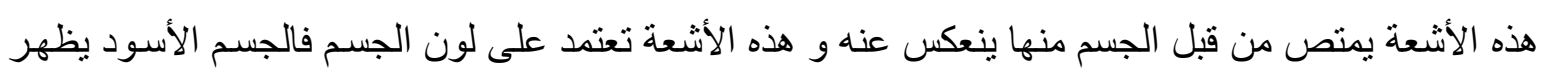

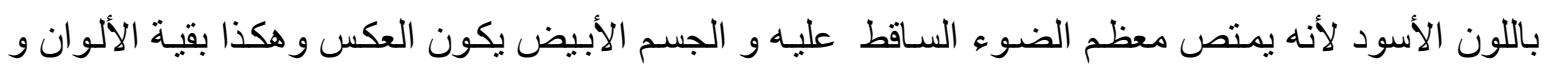


اللون من العناصر الأساسية في تصميم الثعار ات كما تراه الباحثة حيث يستخدم اللون في هذا المجال مغز اه الرمزي فهو يحمل دلالات متعددة ويظهر دور المصدم في كيفيـة تنظيم الألوان لكي تثو افق مع مقياس محدد للشكل (§Y) وتحقيق عنصر الجذب و الوحدة في التصميم مع مر اعات الأداء الوظيفي للشعار.

\section{: Design principles أسس التصميز}

وهي تعرف على انها قانون العلاقات أو خطة التنظيم والتـي بموجبها تتحدد الطريقة التي تتكون

بو اسطتها العناصر وتنقى الأهمية للكيفية التي تنظم بها هذه العناصر وما تخلقه من علاقات متبادلة فيما بينها وما تحدثه من تأثثر لدى المشاهد. والتأثير الذي يظهر في المكون التصميمي (الثـعار) هو ناتج عن العلاقة المتبادلة للأسس التي يحتويها وهي تختلف من تصميم إلى آخر فقد تستخدم بعض التصايريم التصائ جميع الأسس بينما بعضها الآخر يستخدم قسما منها (^^). ويظهر ذلك و اضحا في تصاميم الشعار ات و التي اعتمدت على نوعين

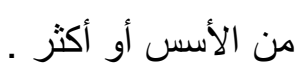

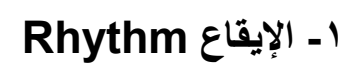

هو التنظيم للفو اصل الموجودة بين وحدات أثنكال التصميم بشكل يبعث الثـعور بالحركة على فضـاء التصميم ـ (9) ويسمى بالتكر ار أو التعاقب و استمرارية للوحدات و الفرق بين وحده وأخرى هو موقعها في

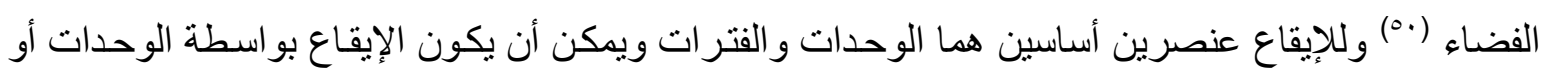

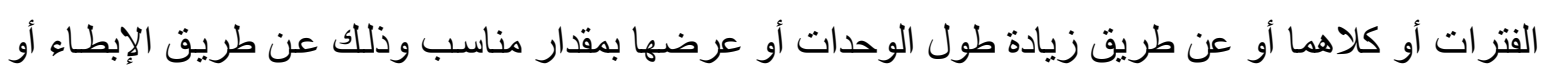
الإسر اع في الحركة أو التبادل بين وحدتين )(10) والإيقاع متنوع كان يكون رتيبا حيث تتشـابه فيه الوحدات و الفترات أو غير رتيب و الذي تتنـابه فيه الوحدات و الفترات مع اختلاف في الثنكل و الحجم أو يكون حرا فيختلف فيـه شكل الوحدات عن بعضـها مـع اختلاف شكل الفو اصل أو متناقضـا وتكون الوحدات آخذة في

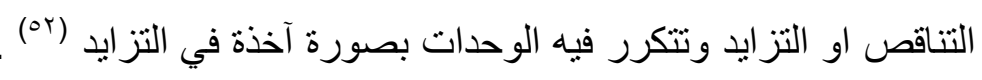

\section{: Harmony الانسجام}

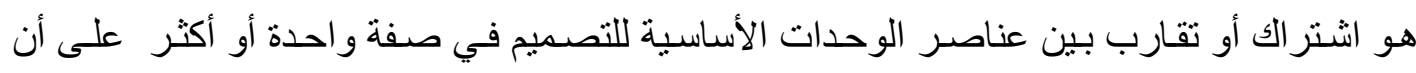

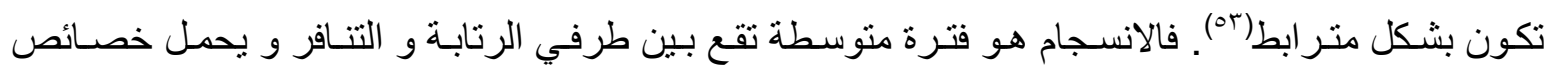

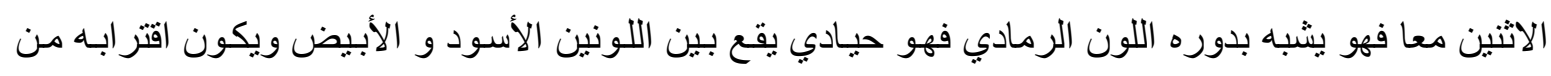

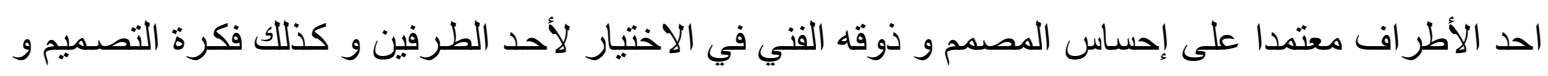
الوظيفة ـ وللانسجام أهمية بالغـة في وحدة العناصر داخل هيئة الثعار ــ والثـعار الذي تظهر في عناصـره سمة الوحدة و الانسجام مع العلاقات التي تجمع بين عناصره يكون قد حقق وظيفة مادية و جمالية .

\section{بـ التباين Contrast}

هو التعبير عن الاختلافات. وهو الصلة بين الأجزاء المختلفة و المتضادة (\&) ويعتبر التباين من أهم قو اعد الثـد البصري حيث يتم التباين مـا بين العناصر و فضـاء الثـعار و تكمن أهميـة استخدام التباين في وهي تصميم الثـعار ات لتحقيق أدر الك الهيئة حيث إن الهيئات تدرك نتيجة لاختلافات في الحقل المرئي إي أنها

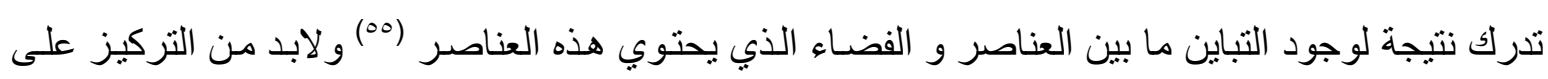
استخدام التباين بين عناصر التصميم لتحقيق الوحدة دون الإفر اط لان ذلك يحطم هذه الوحدة (Tه). 
عـ التوازن Balance

يتضمن التوازن العلاقات بين الأشكال و الألوان و القيم و الملمس.. في التصميم بشكل مستقر (ov) و من أساسيات التصميم و الذي يتحقق بترتيب العناصـر بشكل منسـم أب موازنـة جميع الأجز اء الموجودة في وني حقل مرئي معين و يتطلب ذلك وجود محور مركزي أو موضع تتزن حوله جميع القوى المتعارضة (هـا.

\section{: Proportion التناسب}

هو العلاقة بين شيئين(ه9) وهو العلاقات المصممة للمقاييس منل (الزمن، الفضاء، اللون و القيمة الضوئية، الحجم...) و الذي من خلاله يمكن تحقيق الوحدة والتنوع داخل التصميم مـع تحقيق عنصر الجذب من خـلال تقسيم إلى أجز اء مختلفة ومتعارضـة في الثكل و الحجم بعلاقات تربط العناصـر فيما بينهاو بين التصميم بأكمله (•)". ومن خلال التناسب يمكن تحقيق الوحدة في التصميم ولذا كان ضروريا استخدامه والحاجـة أليه

في تصميم الشعار ات لما تحويه من عناصر مختلفة وضرورة وجود علاقات تناسبية لتنظيمها وتوحيدها

\section{דا}

و هي تغلب عنصر معين داخل التصميم على بقية عناصر التصميم والتي تعتبر هذه العناصر من مكملات هذه المكون (آ) وتختلف السيادة في التصميم حسب الهدف الوظيفي(*) للتصميم فقد تكون السيادة في

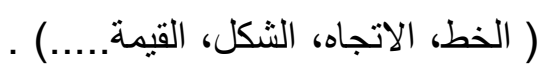

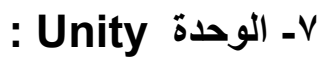

هي مبدأ أساسي للتنظيم الجمالي للتكوين التصميمي .وقد سهي بالتكوين نظر الأنه يحتوي على نظام

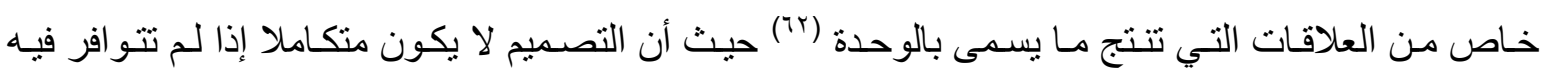
الوحدة و ألا لأصبحت العناصر غير منر ابطة ومنفلتة وتتحقق الوحدة في الشكل ضمن اعتبارين: A-علاقة الجزء بالجزء: أي أسلوب ربط كل العناصر مع بعضها. B-علاقة الجزء بالكل: أسلوب وصل كل عنصر ولهر

بالثكل العام للتصميم. (rآ).

: variety التنوع

هو من العمليات الأساسية في التصميم بالإضـافة إلى الوحدة و التر ابط فهو يمثل (๕ج) الحيويـة في العمل التصميمي و هو مهم في تصميم الثـعار ات لتحقيق الجاذبيـة باعتبار أن حدود فضـاء الثـعار هي حدود نعتبر ها ضيقة ولذا تكمن مهارة المصمم في كيفية أحداث التباين بين العناصر داخل الحدود لتحقيق الجمالية في المكون التصميمي.

: Typography العناصر التيبوغرافية في الشعاري التيبوغرافيا : هي علم وفن الهيئات المطبو عة وما يتعلق بماهية هذه الهيئات وتتاولها واستخدامها فوق فضـاء

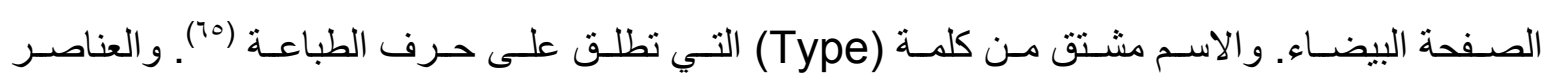
التيبو غر افية المنمثلة بالخطو الرسوم و غير هـا هي من العناصر المهمة و التي تلعب دور المهمـا في تصميم

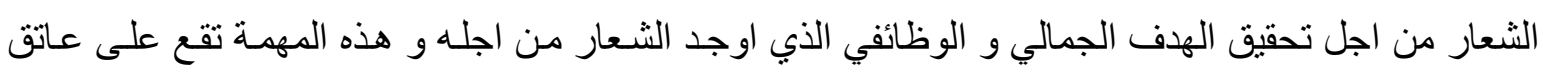
المصمم ألطبـاعي في توظيف هذه الخطوط بالأسلوب الذي يحقق عنصـر الجذب والتوازن و الوحدة في التصميم. ويعتبر الخط من ابرز العناصر التي وظفها المصمم في الثـعارات باعتباره من العوامل التي تسـهل 
عملية الاتصال لغرض إيصال ما يرغب بايصاله المصمم إلى المتلقي وكذللك باعتبار الخط من أهم السمات

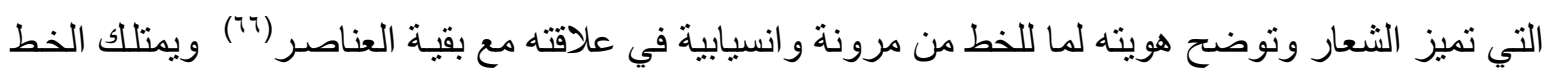
طاقات تعبيريـة إضـافية من خلال تغير سمكة ومدى تبدل شكله أو أثبـات ذلك الثكل( يرفعع، يسمك....الخ)

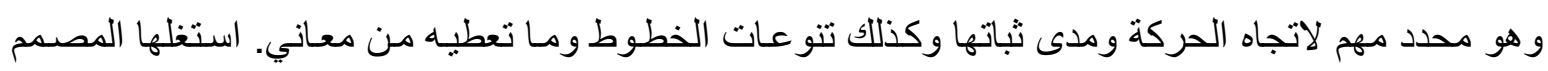

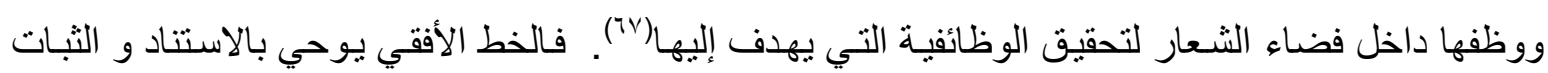
و السكون و الخط العمودي يوحي بحركة مقاومة الجاذبيـة وتجميع الخطوط مـع بعضهـا يوحي بقوة رفع تجاه

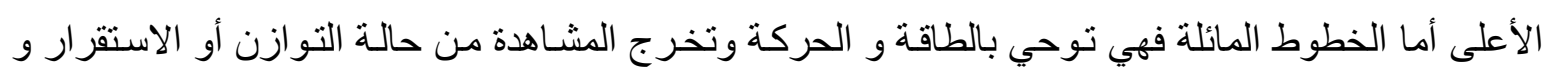
كنتيجة لذلك فأن الخط بإمكانه أن يقدم سطوحا موحية وذات دلالة واضحة و وعيقة و للخط أهمية بالغة ومكانة

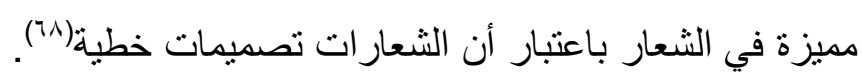

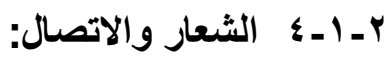
هناك علاقة بين الثعار و الاتصال تنشا من خلال أهمية الأشكال في الاتصال حيث تزداد أهيـة هذه الإشكال عندما تزداد حجم المنافسة بين وسائل الاتصال المختلفة . ويأتي دور المصمم في الدمج بين الاتصـال و الإبداع لكي نحصل على الاتصال المطبوع الفعال من خلال تحقيق عنصر الجذب و الاهتمـام وكذللك تقديم الفكرة بشكل و اضح للوصول إلى الإبداع و الإقناع و الاستجابة والاتصـال Communication هو عملية

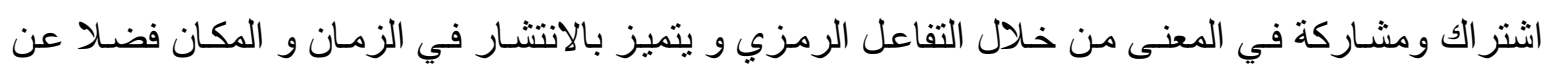

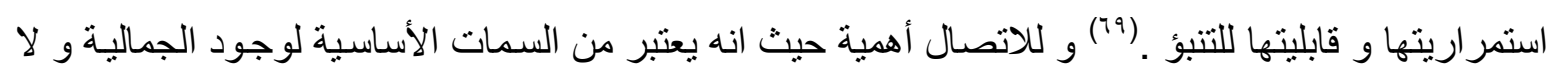
يمكن لوجود الجماعة بدون اتصـال و أن نزعة الاتصـال موجودة للدى الإنسـان بحكم الغريزة لذا فهو نتيجة حتمية لوجود الجماعة فتجارب الإفراد وخبر اتهم ومكتسبا تهم تنقل للآخرين بطريقة الاتصـال لأنه الوسيلة

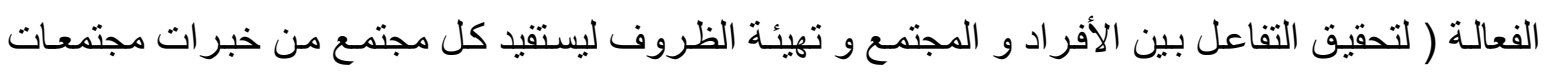

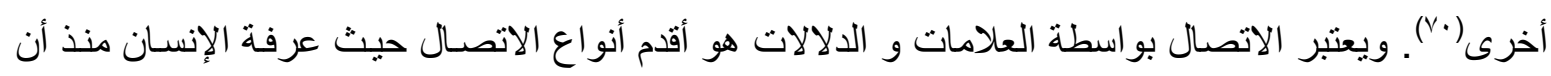

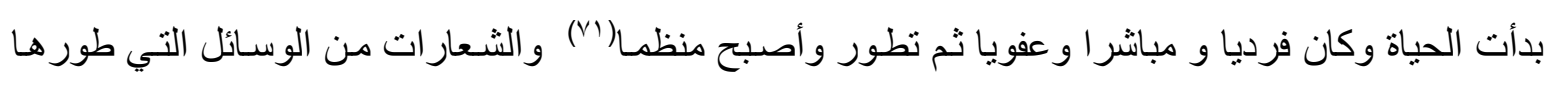

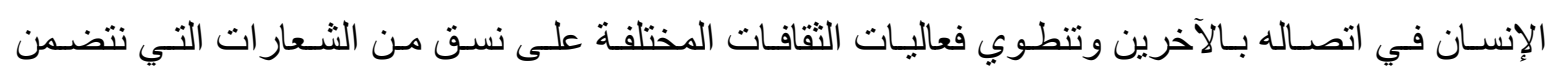

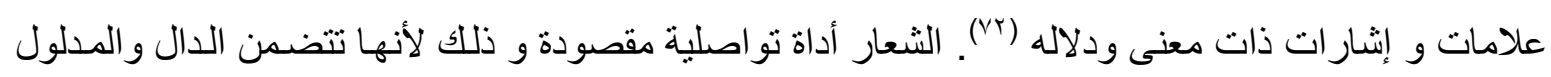

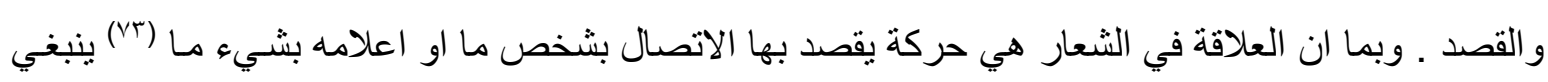

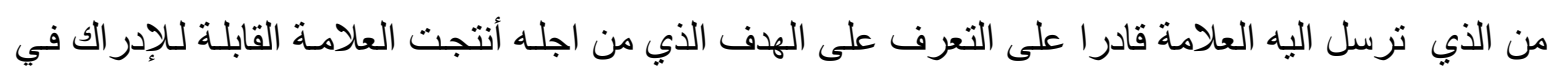

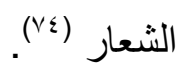

\section{r ـ ـ إه الثعار و استخداماته الوظيفية و البصرية:}

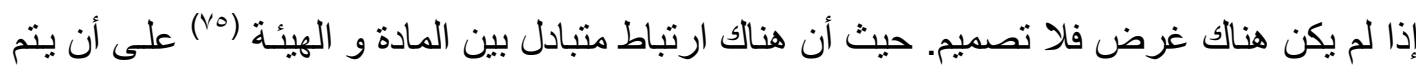
ذلك في عملية خلق تصميم ذات أهداف جمالية بالإضـافة إلى الأهداف الوظيفية ،فالخطوط التوجيهية العامـة

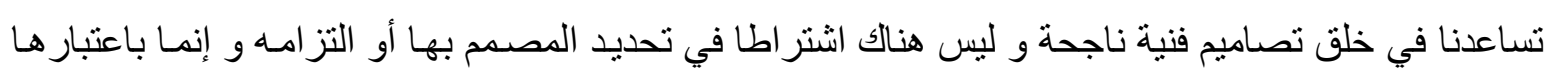
وسيلة أو لغـة مرئيسة من اجل إيصـال فكرة معينـة من خـلال توظيف العناصـر داخل التصميم لتعطي ناتجـا

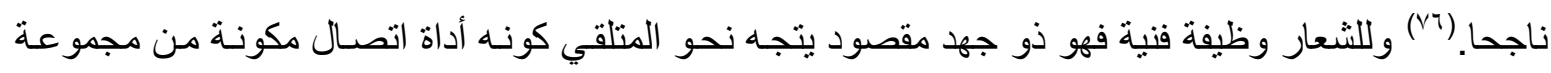


أثـكال و رموز تهدف إلى التـأثير في المتلقي و مخاطبته. لذا فـأن الثـعار يتطلب أسـاليب معينـة لدراسـة الوظـائف و العلاقات .. و هـي مسؤولية كبيرة تقع على عـاتق المصمم فهو يقوم بتحقيق المعادلة التصـيمية المتكاملة والتي تعتمد على استخدام القواعد الفنية و العملية التي تخلق تصميم مميز للثـعار ممتلكا لعنصر الجذب من خلال هيئته العامة و التي تخلق انطباعـا مرئيا متحقق من النظرة الأولى مـع مقدرة المصدم على ولى

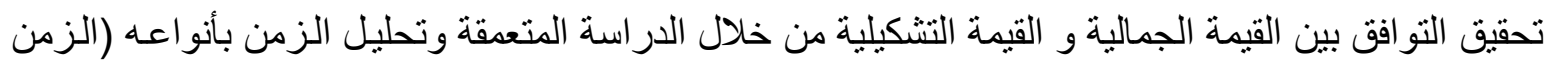

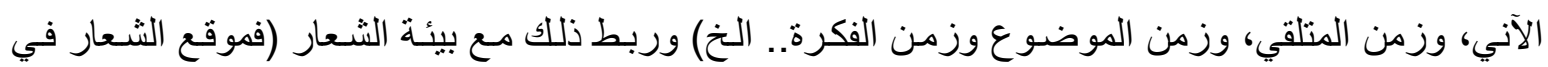

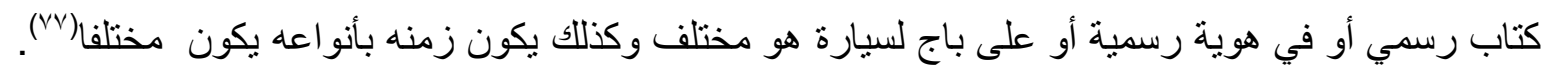

\section{ـ ت تنوع الثكل مع ثبات الوظيفة}

أن التصميم الذي يخدم وظيفة معينة يمكن أن يظهر في أكثر من شكل وأن الإشكال غير ثابتـة وقد تتنوع وتتغير في الثـعارات مع ثبـات الوظيفة فقد تتغير الخطوط أو المساحات أو الألوان وتتتوع وتتـر ابط الإس

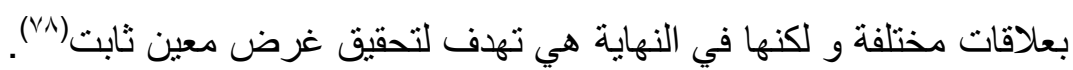
r- إجراعات البحث: يتضمن هذا الفصل الإجراءات التي اتبعتها الباحثة وهي كما يلي: rـ ا طرق البحث: اعتمدت الباحثة على ( المـنهج الوصفي التحليلي) في جمـع المعلومـات و البيانـات مـن النماذج المستنسخة للشعار ات.

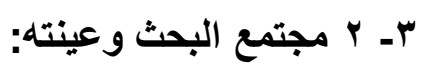
يتكون المجتمـع الأصـلي للبحـث مـن كافـة شـعار ات جامعـات القطر الرسـية و البـالغ عددها سـبع شـعار ات(") لذا اعتبرت الباحثة مـا حصلت عليه بمثل عينـة ممثلة للمجتمع الأصلي و التي تشمل (تصميم شعار جامعة بغداد -شكل ( ()/ تصميم شعار الجامعة ألمستتصرية ـ شكل (r)/ تصميم شعار جامعة البصرة

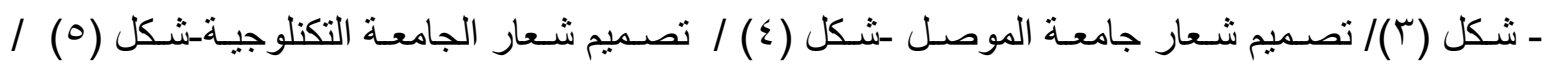

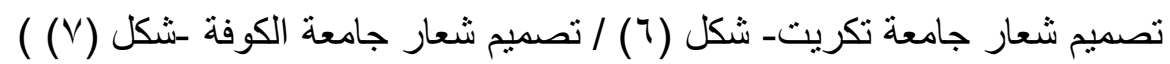

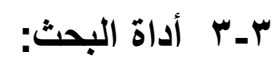

بغيـة الكثـف عن التنظيم الثـكلي في أسسيه العلاماتيـة لثـعار ات جامعـات القطر ولتحقبق أهداف البحث قامت الباحثة بأعداد استمارة تحديد* مقنتة لتحديد محاور التحليل الأساسية تمخضت محاور هـا عن الإطـار النظري للبحث. وتضمنت الاستمارة خمسـة محساور رئيسية ( التنظيم الثنكلي ، الكل العـام وفاعلية

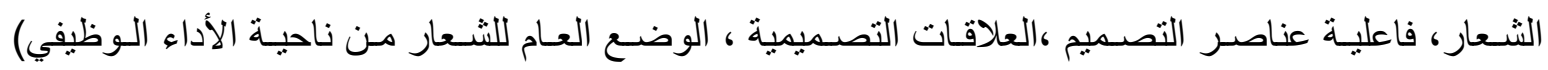
وتضمن كل محور فقرات تفصيلية.

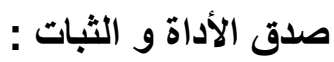

تم التحقق من الصدق الظاهري لفقرات استمارة البحث المستخدمة لجمع المعلومـات وذلك بعرضـها قبل تطبيقها على لجنة المتخصصين في مجال مناهج البحث العلمي و التصميم وقد تم الاتفاق ( . ( \% ) على جميع فقرات استمارة التحديد.لغرض التأكد من صدق التحليل قامت الباحثة بعرض نماذج التحليل على خبر اء

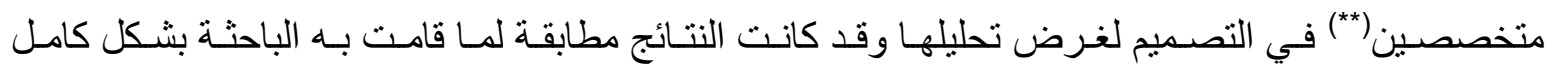


ـ - مناقشة مجتمع البحث

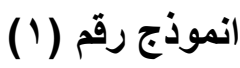

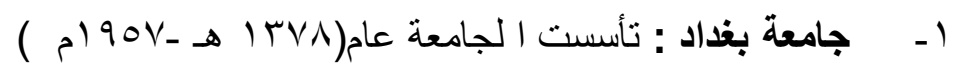

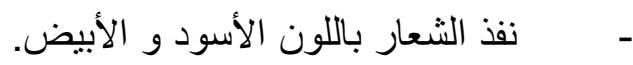

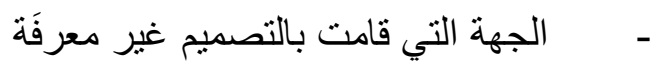

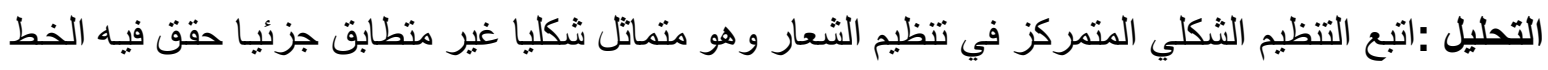

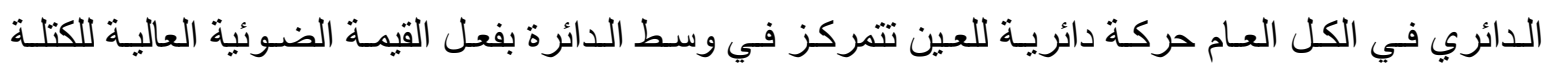

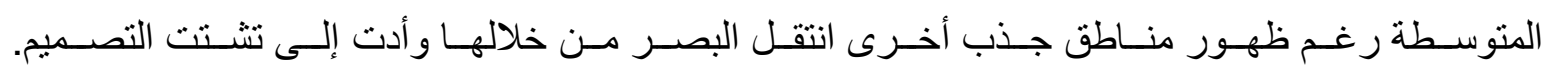

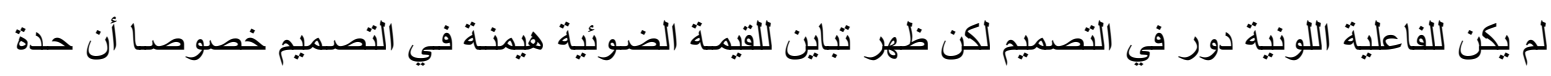

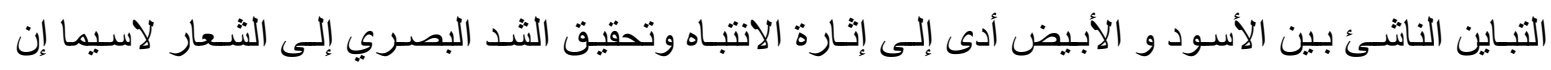

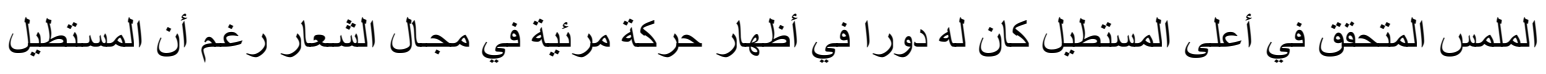

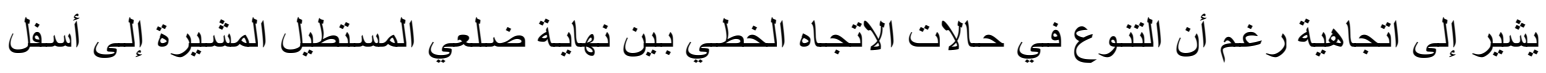

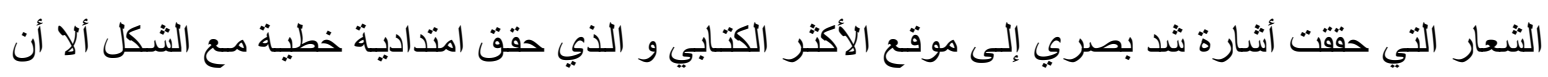

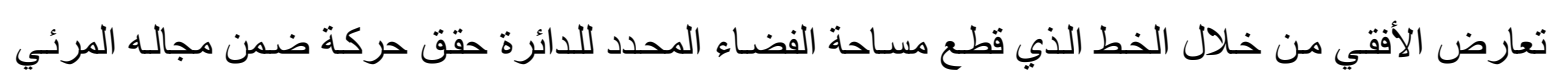

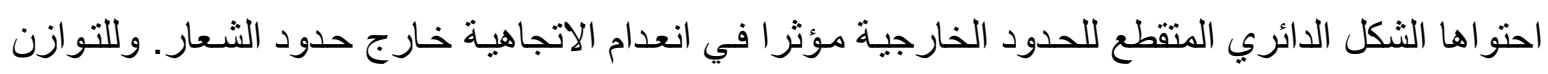

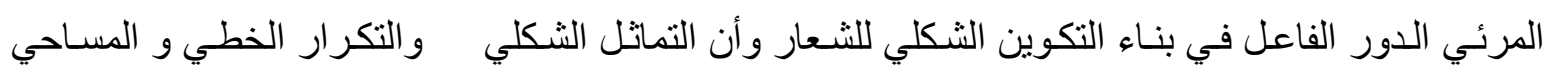

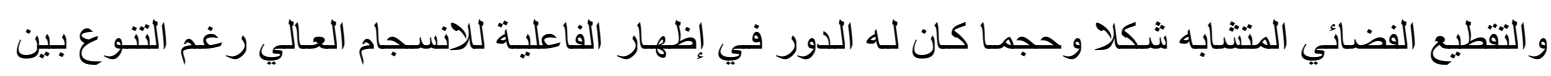

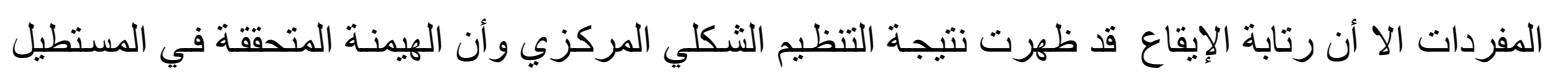

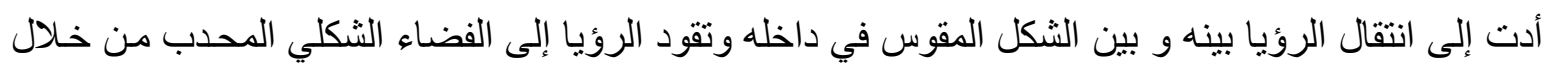

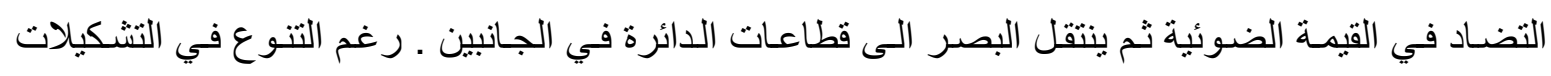

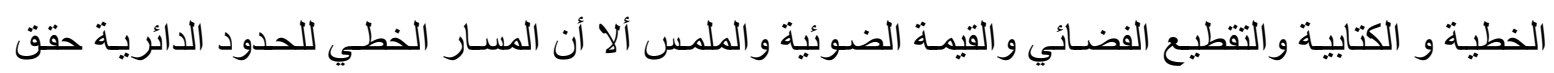
الوحدة في تصميم الثعار و عززها التنظيم الثكلي المركزي .

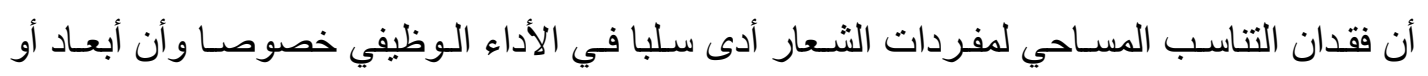

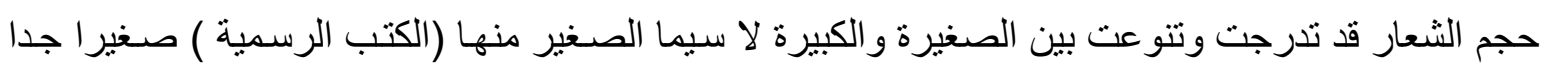

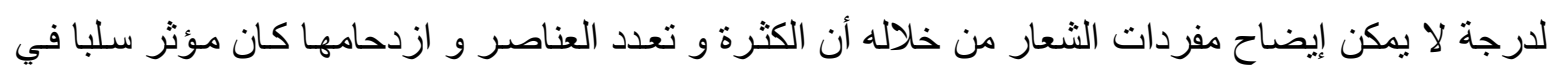

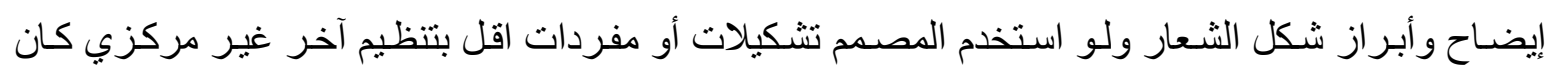

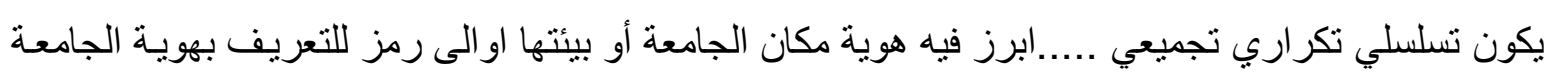

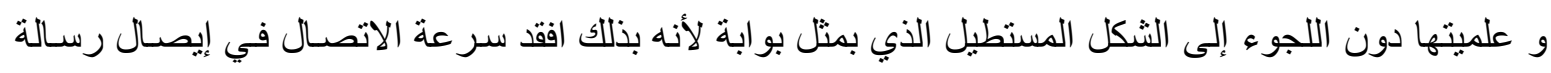

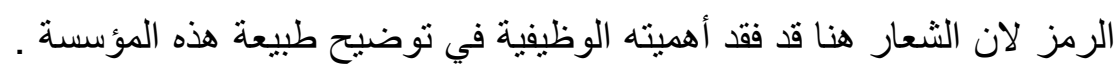


- نفذ الشعار باللون الأسود و الأبيض.

ـ لم تعرف الجهة التي قامت بالتصميم.

التحليل: التنظيم الثكلي المتبع فيه الرمز هو تنظيم مركزي تجميعي تسلسلي حقق فيه الخط الدائري المحدد لفضاء الثعار و الحركة الخطية الدائريـة في حدود الكل العام حركة دائريـة للعين تتمركز في وسط الدائرة

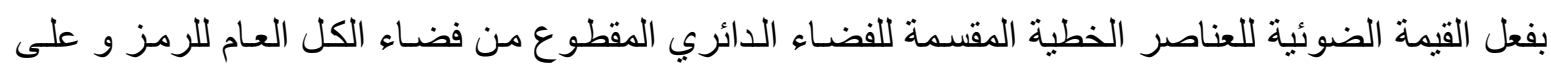

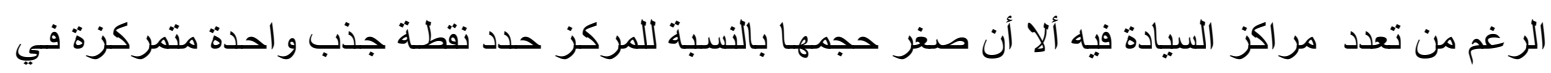
وسط الشعار. . ولم يكن للفاعلية اللونية دور في التصميم لكن ظهر تباين القيمة الضوئية حقق نوعا من الهيمنة

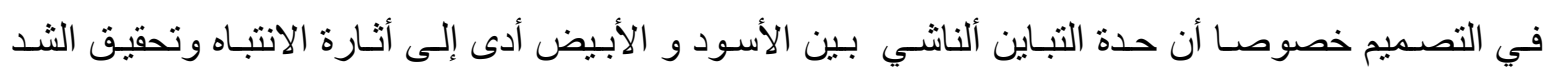

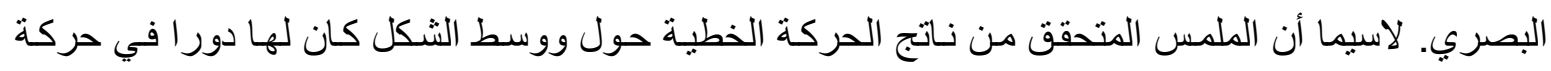
مرئية في مجال الثعار. ويظهر اتصال الخطوط مع بعضها وتر ابطها على هيئة سلسلة تحيط بمركز الثعار إلى الاتجاه الخطي الذي يشير إلى أسفل الشعار و يسهم الوجود الشكلي للمفردة المتكررة على جانبي الثعار

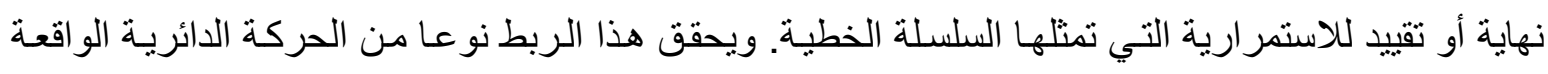

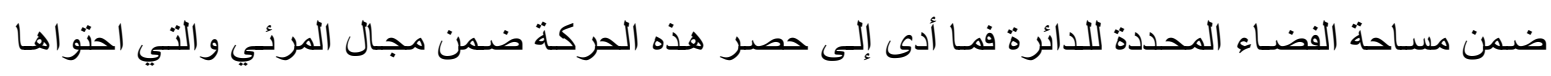
فضاءه مكونا حركة داخلية ضمينة في المجال مؤثرة في تحديد الاتجاهية إلى داخل حدود الثعار بمسـاعدة الاتجاه الخطي ـ وكان التماثل الثكلي و المسـاحي و التكرار و التقطيع الفضـائي المتشـابه شكلا و حجمـا لـه

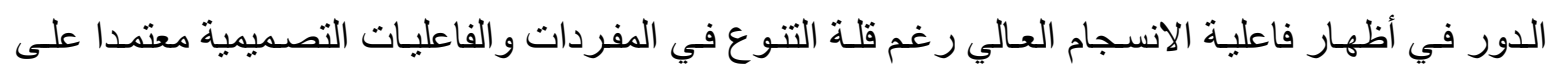
العنصر الخطي فقط حيث ظهرت رتابـة الإيقاع نتيجـة التنظيم الثكلي المركزي وأن الهيمنـة المتحققة في الثكل الخطي الدائري المحيطو التشكيلات الخطية المتمركزة في وسط الثعار أدت إلى نوع من الانتقال في الرؤيا بين المركز و بين مـا يحبط بـه مـن عناصر و سـاعد على هذا الانتقال التضـاد في القيمـة الضـوئية. ورغم التنوع في التشكيلات الخطية و الكتابية و التقطيع الفضـائي فقد تحققت الوحدة في التصميم و عززهـا التنظيم الثكلي المتبع بالإضافة إلى تحقيق عنصر الجذب و الثـد البصري. و على الرغم من وجود التناسب المساحي لمفردات الثعار ألا أن ذلك لـ يمنع من الأداء السلبي الوظيفي بسب الإفر اط في استخدام العنصر الخطي و التباين في القيمة الضـوئية الحالي خصوصـا وأن أبعاد الجسم و حجمهـ قد تدرج إلى صغير وكبير ولو أن المصمم استخدام مفردات أو تشكيلات أخرى غير خطية لإبر از اسم المؤسسـة بالإضـافة إلى أن هنالك

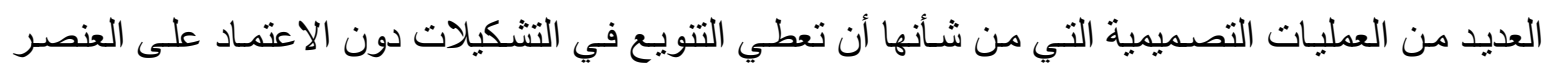
الخطي فقط.

( انموذج رقم (ب)

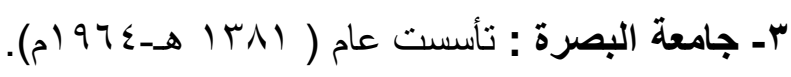
- نفذ الشعار بالألوان ( ازرق__ اخضر _ _ اصفر _ ـ أسود).

- صمم الشعار ( د. مؤيد عبد الصمد عميد كلية الفنون الجميلة- جامعة البصرة). التحليل: استخدام في تصميم الثـعار التنظيم الثكلي المتمركز حول ذاته وبسبب المبدأ التجميعي في تنظيم المفردات فقد ظهر واضحا أدر اك الكل العام للثعار دون الأجز اء. حقق فيه الخط الدائري حركة دائريـة للعين 
تتمركز في الوسط. وبسبب الاختلاف في سمك الخط لمحيط الدائرة و الثكل المثلث أعطى ذلك تباينا على في القيمة الضوئية لأركان المنلث. وقد أدى ازدحام الأشكال داخل المثلث أدى إلى الاختلال في نقل مبالغ بـه في

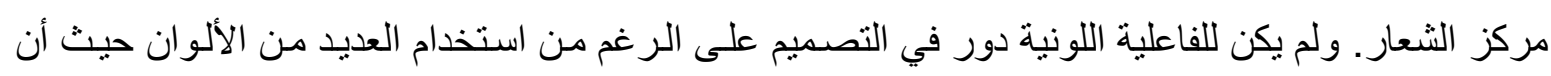

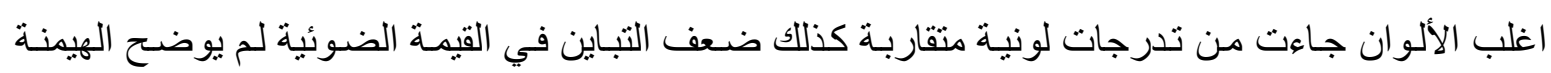
لأحد التشكيلات. ويظهر التركيب الملمس للأشكال حركة ضعيفة بسبب الازدحام بين العناصر داخل مركز

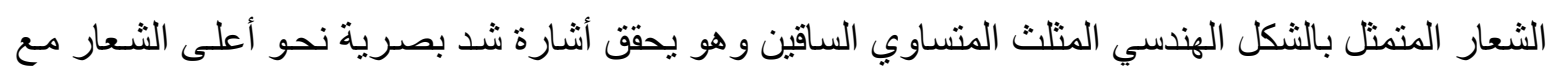
التكوينات الثكلية داخل الثكل أيضا تشير إلى أعلى الرمز و إلى الحدود الخارجية للشعار ـ. ويظهر التوازن

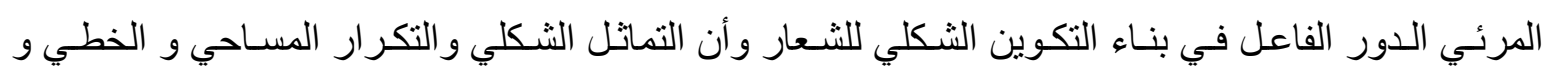
التقطيع الفضـائي شكلا وحجما لـه الدور في أظهار فاعليـة الانسجام رغم التنوع بين المفردات ألا أن رتابـة ولنة الإيقاع قد ظهرت نتيجـة التنظيم الثكلي المتمركز. وتظهر الوحدة في تصميم الرمز بفعل التنظيم ألا أن

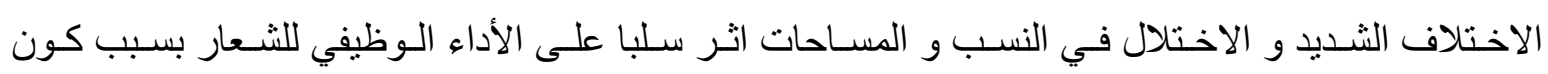

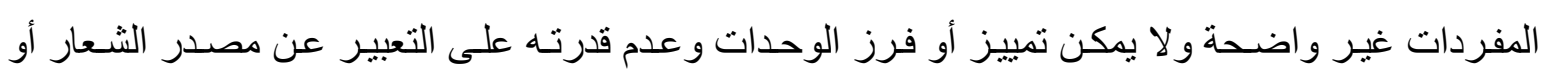

الجامعة التي صدر عنها .

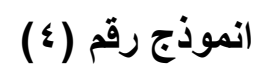

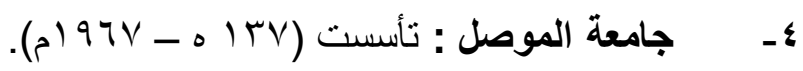

$$
\begin{aligned}
& \text { الألوان المستخدمة ( الأحمر_ازرق_ـابيض_اسود) }
\end{aligned}
$$

- - الجهة التي صممت الثعار : احد الفنانين و هو أستاذ في نفس الجامعة.

التحليل: أن التنظيم المتبع في تصميم الثـعار هو التنظيم المركزي حقق الخط الدائري المحدد للكل العام حركة دائرية تتمركز في وسط الدائرة بفعل القيمـة الضوئية العاليـة للكتلـة الدائريـة بوسط الثـعار رغم رغم تعدد المفردات التي تمثنل مناطق جذب أخرى التي أدت إلى انتقال الرؤيـا بين الفضـاءات الموجودة ضمنا بوسط الدائرة ويساهم التنظيم المتمركز بتحقيق الثد البصري إلى وسط الدائرة اذ يتحقق الإدراك للكل العام للشعار أدى التباين في القيم اللونيـة التي جاءت بهيئة كتل لونيـة قسمت الفضـاء العام للثعار إلى أثنارة الانتباه وتحقيق الثد البصري إلى الثـعار لاسيما أن الملمس المتحقق في أعلى الثـعار و أسفله و على الجانبين في داخل المستطيل التي يتوسط الثعار بشكل امتداده أفقي مقطوع من الوسطو الذي لله دور في أظهار حركة

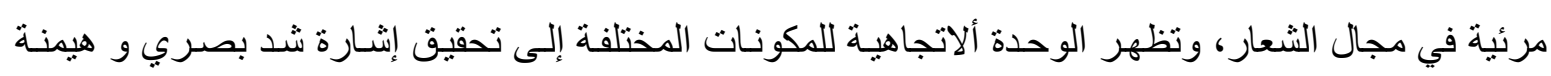
باتجاه الأعلى وبضمنها الأثر الخطي في أسفل الثـعار ــ وللتوازن المرئي الدور الفاعل في بنـاء التكوين الثكلي للشعار و التماتل كان له دور في أظهار الفاعلية و الانسجام العالي رغم التنوع الحاصل بين المفردات

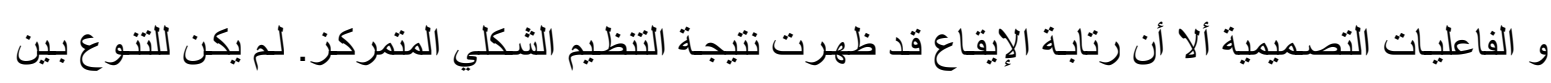
المفردات وظيفة حيث تميزت هذه الوحدات بالافتقار إلى التنوع و نتيجـة الوحدة في ظاهرة التصميم و أتباع المبدأ السيميائي في التعبير عن هوية المؤسسة فقد كان أداء الثعار ايجابيا من الناحية الوظيفية حيث استطاع أن يحقق الهدف الأساسي في تصميم الثعار . 
(0) (نموذج رقم (0)

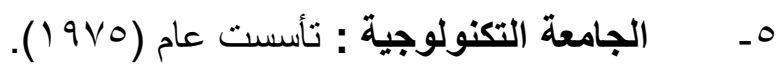

الألوان المستخدمة (الأسود_ـ_الأزرق).

قام بتصميم الشعار ( قسم العلاقات بالجامعة).

التحليل: ويظهر الثعار بتنظيم تركيبي منمركز منماتل كليا ومنطابق حقق فيه التباين اللوني للكتل في جهني التصميم نوعا من الحركة و بسبب الترابطو التجانس الحاصل في أجز اء التصميم و التباين في القيم الضوئية بين الكتل الموجبة المتمثلة لأجزاء الثعار و الفضاءات السـالبة المتمثلة بالفضـاء المحيط فقد نتج عنه الفضـاء المحصور في وسط الثـعار الذي تحول إلى فضـاء موجب مثنل مركز السيادة ونقطة شد بصري حيث تم أدراك العام بفعل التر ابط بين الأجزاء و يظهر التباين في القيم الضوئية واللونية ووضوح التضـاد بين الفضـاء

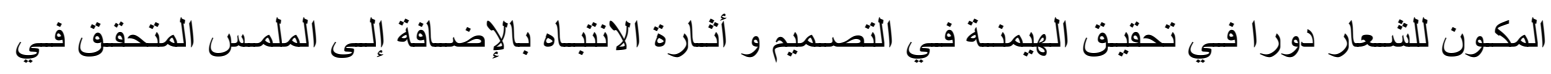

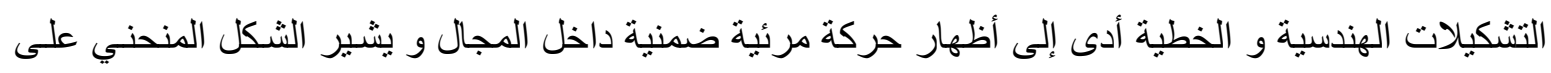

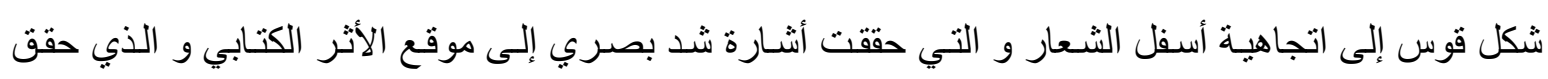

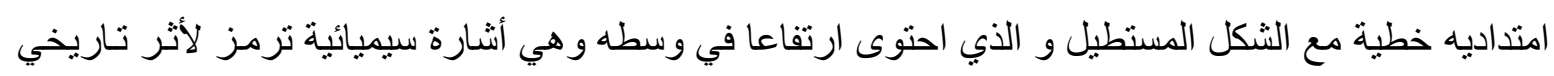

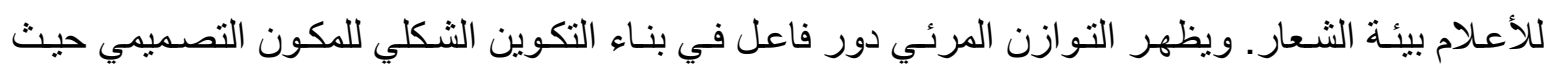

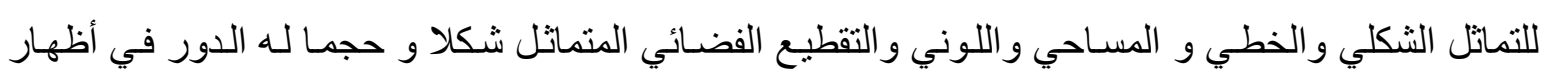

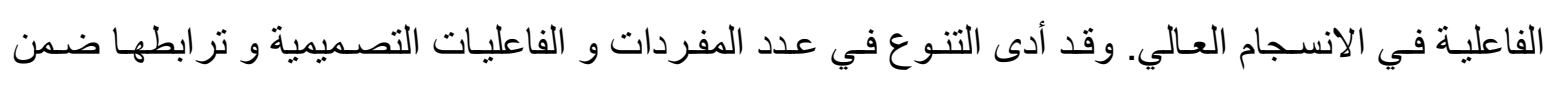
التنظيم التركيبي إلى انتقال الرؤيا إلى الفضـاء الثكلي في وسط الرمز ومن خـلال التضـاد في القيمـة الضـوئية و للتوازن الثكلي دور في تحقيق الوحدة التصميمية بالإضافة إلى التناسب المساحي للمفردات في الثسعار أدى إنى إلى تحقيق الأداء الوظيفي فقد تمكن الثعار من التعريف ببيئة التصميم من خلال الثكل المقوس وهو علاقة بلة

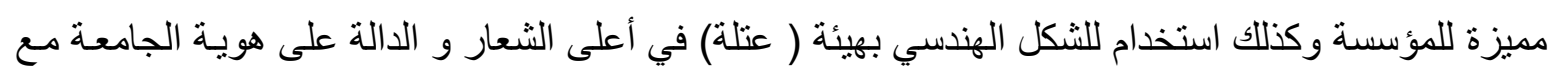

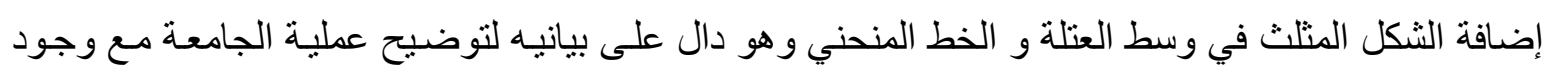

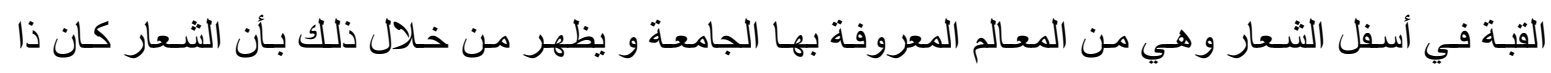
تصميم ناضج وناجح في إيصال الرسالة و تحقيق الهدف في الأعلام بطبيعة المؤسسة التي انشأ من اجله

انموذج رقم (1)

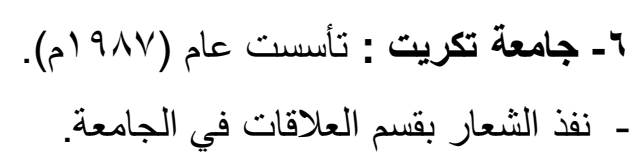

التحليل: أن التظظيم الثنلي المتبع فيه الثعار هو تنظيم مركزي توسعي حققت فيه الخطوط المحددة للكل العام للثـعار والتبـاين الحاصـل في القيمـة الضـوئية إلى أظهار حركة مرئيسة في الثـعار وتحديد مركز للسياحة

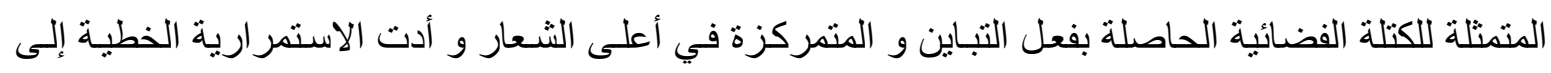
أدر الك الكل العام دون الأجز اء. ولم يكن للفاعلية اللونية دور في التصميم لكن ظهر التباين في القيمـة الضوئية أعطاه نوعا من الهيمنة خصوصا أن حدة التباين ألناشي بين اللونين الأسود والأبيض أدى إلى فئى أثنارة الانتباه و 
تحقيق الثد البصري لاسيما أن الملمس المتحقق في أعلى الثـعار كان له دورا في أظهار حركة مرئية في

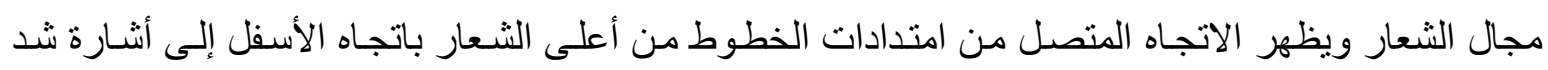
بصرية إلى موقع الأثر الكتابي حيث التعارض الأفقي للأثر يعطي نوعا من الحركة التي احتواهـا الثكل بــ يسبب الارتباط الحاصل بين الامتدادات الخطة ـ و التوازن المرئي دور فعال في بناء التكوين التشكيلي للشعار

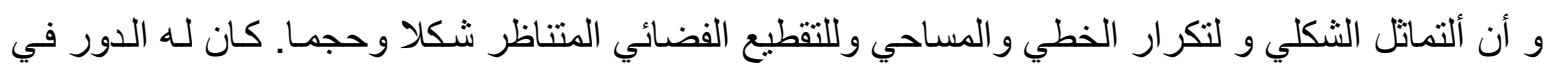
أظهار الفاعلية للانسجام العـالي مع وضوح الهيمنة الثكل الهندسي الناتج بفعل التكسرات الخطيـة في أعلى ولى الثعار.ويسبب افتقار الرمز إلى التتوع في المفردات واعتمـاد على التنويعات الخطية إلى التأثير سلبا على الأداء الوظيفي الثعار على الرغم من تحقيق الوحدة و الانسجام يسبب التنظيم المتمركز ممـا يؤدي ذلك إلى لى ضعف التصميم من خلال عدم قدرته على التعريف بيئة الشعار وبعلمية الجامعة

(V) انموذج رقم (1)

$$
\begin{aligned}
& \text { V- جامعة الكوفة : تأسست عام (9^v (م) } \\
& \text { - }
\end{aligned}
$$

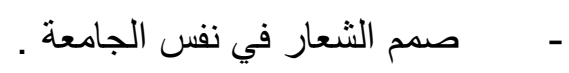

التحليل: التنظيم السائد في الرمز هو تنظيم تجميعي منمركز حقق فيه الخط الدائري المحدد للكل العام حركة دائرية للعين تتمركز في وسط الثعار بفعل القيمة الضوئية للكتلة المتوسطة الناتجة من تجميع المفردات وسط فضاء الثعار بسبب المبدأ التجميعي المتبع أدى إلى إدر الك الكل دون الأجزاء المكونة للشعار مع تحديد منطقة جذب واضحة متحققة في وسط الكل العام. ولم يكن للفعالية اللونية دور في التصميم لكن ظهر تباين في القيمة

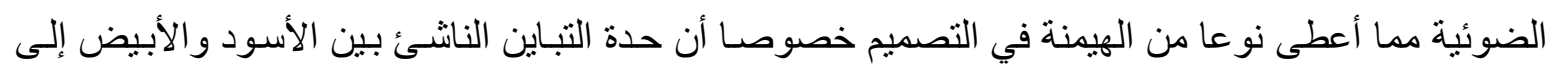
أثنارة الانتبـاه وتحقيق الثـد البصـري إلى الثـعار وكـان له دور في إظهار حركة مرئيسة في مجـال الثـعار. ويتضح ذلك في المسار الخطي الدائري الوهمي المحيط للمركز المتمثل في سمك الخط و اتسـاع مساحة التباين بين منطقة الظل و الضوء في فضاء الثعار مع وضوح الجانب ألملمسي في شكل الظـاهر التصميمي المتحقق في الفضـاء الدائري المتمركز وسط الثـعار ويظهر التكرار الرتيب للوحدات المنسلسلة بهيئة حلقة دائريـة محيطة بالثكل المتمركز في وسط الشعار نوعا من الحركة الدائريـة الضمنية والناتجـة بفعل الاتجاه الخطي

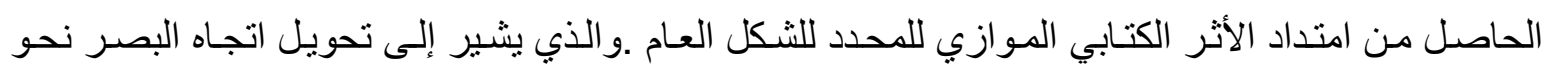
المركز ـ ويظهر التعارض الأفقي الناتج من خلال الخط الموازي لخط الأرض والذي ينصف مسـاحة الفضـاء المحدد للدائرة قد حقق حركة بصرية متنقلة لجانبي الثـعار لم يحقق التوازن المرئي دوره في أعلى وأسفل الثعار من جر اء استخدام الوحدات المتباينة في القيمة الضوئية وان التماتل الثكلي والتكرار الخطي و التقطيع الفضائي المتشابه شكلا وحجما كان لـه الدور في إظهار الفاعلية للانسجام العالي رغم التنوع في المفردات و التباين في حجمها و الافتقار إلى التناسب المساحي بين الفضـاءات الداخلة في كل الثـعار مـ تحديد الهيمنة و السيادة بفعل انتقال الرؤيا في مركز الثعار الى التشكيل الخطي المتحرك حوله ثم العودة عن طريق الحركة الداخلية للشكل الدائري إلى الفضـاءات المتتابعة المحيطة بـالمركز. وسبب التنظيم الثـلي المتمركز وحدة 
شكلية في التصميم لما يوحيه هذا التنظيم من حركة دائرية حول مركزة. أدى فقدان التناسب المساحي إلى أثر سلبي وظيفي للشعار حيث تظهر أهمية القياس والأبعاد والأحجام بالنسبة لاستخدامات الثعار ،لذلك لم تظهر

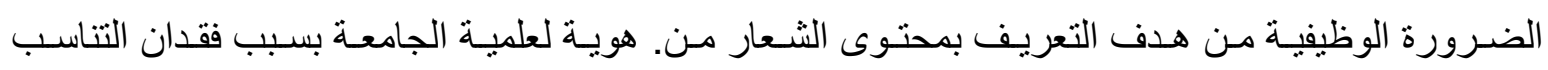

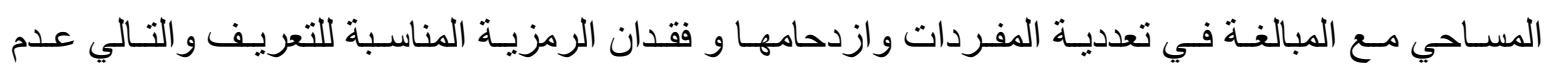
وضوحها ظاهريا.

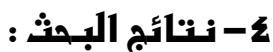

ا ـ أن التنظيم الثـكلي المتمركز هـو التنظيم السـائد في تصـيم الثـعار ات تـلاه التنظيم الثـكلي التجميعي المتر اكب تلاه التنظيم الثكلي التوسعي وظهر أن التنظيم الثكلي المتمركز هو أكثر الأنظمة المستخدمة في

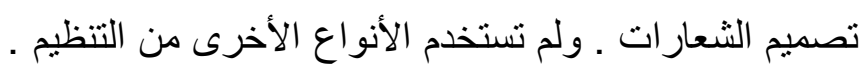
ז- لم يحقق التنظيم الثكلي المتبع في الثعار ات علاقة في أسس تصميم العلامات فقد ظهر أن (اللون والحجم و الاتجاه و الملمس ) دورا ضعيفا • اما القيمة الضوئية فقد كان لها دورا ايجابيا في تصميم الشعارات זـ لم يكن لأسس العلائقية للشعار ات دور ا واضحا وايجابيا في التنظيم الشكلي للشعار ات حيث ظهر أن كل من.(الايقاع ، التناسب ، التتوع ، التوازن) هي علاقات سلبية في أداءهـا التصميمي عدا كل من (الانسجام ، التباين، السيادة) فقد كانت ذا دوراي ايجابي في التنظيم . عـ ـ لم تحقق غالبية الثعار ات الأداء الوظيفي والذي أنشئ الشعار من اجل تحقيقه بالدرجة الأولى .

- التوصبات:

اـ أظهرت نتائج البحث استخدام التنظيم الثكلي المتمركز بالدرجـة الأولى في تصميم الثـعار ات ثم تـلاه التركيبي ثم التوسعي ولذا فان الباحثة ترى ضرورة استخدام الأنواع الأخرى والمتعددة للتنظيم في الثعار ات r- أظهرت النتائج أن اغلب العناصـر التصميمية لم تستخدم بشكل ايجـابي في التصميم وعليه فـان الباحثة توصسي بضرورة استغلال هذه العناصـر من لون وخط واتجـاه في تحريكها في فضـاءها في التصميم ذو البعدين من اجل الوصول إلى نتائج منطقية . ז- ظهر أن هناك دور ا ضعيفا لأسس العلائقية للشعار ات وعليه تقترح الباحثة ضرورة الاستخدام الأمثل لهذه الأسس و العلاقات المتتلمة بـ (الإيقاع التناسب التنوع التوازن). ع - ظهر في نتائج البحث عدم قدرة الثـعار ات على الأداء الوظيفي الايجابي و عليه توصـي الباحثة بالتأكيد على هذا الجانب في تصميم الشعارات .

\section{- المقترحات :}

ا ـ اقتصر البحث على دراسة وتحليل تصـاميم الثـعار ات للجامعات العر اقية الرسمية فقطوترى الباحثة ان هناك حاجة لار اسة تصاميم الثعار ات للجامعات غير الرسمية (الاهلية). 


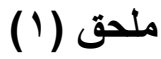
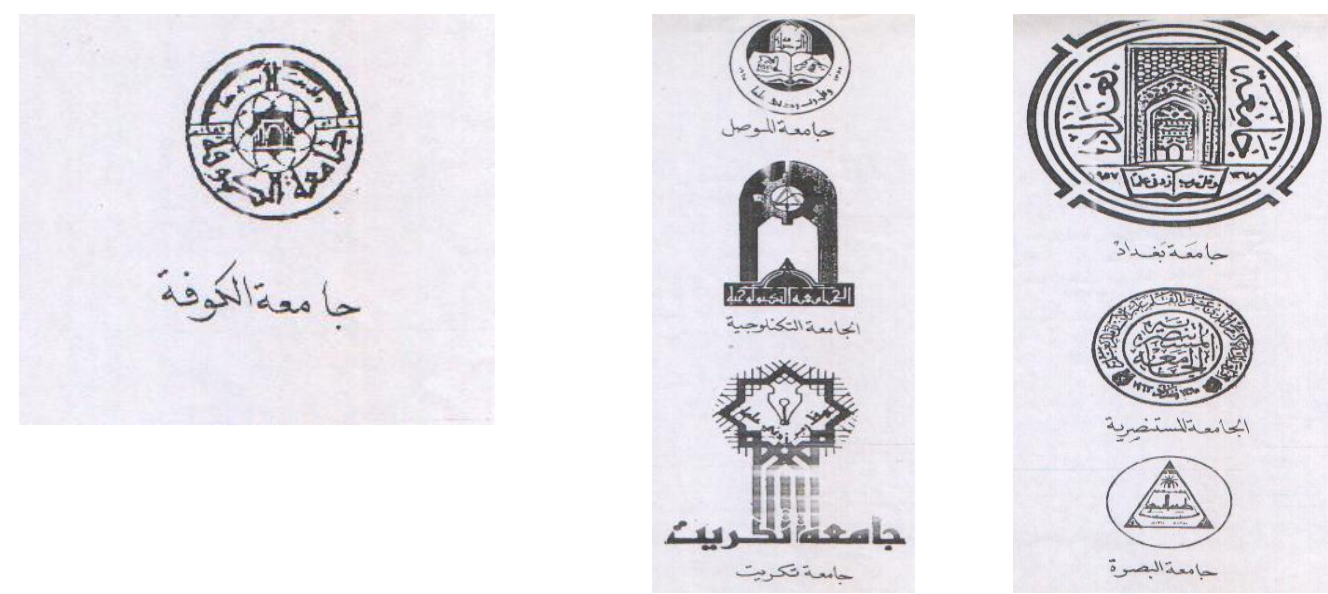

الهوامش

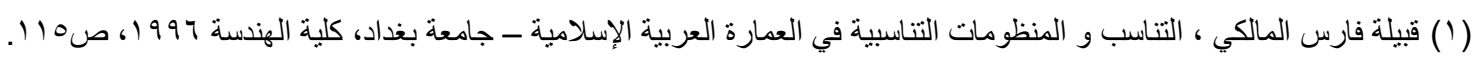

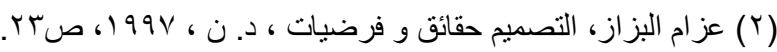

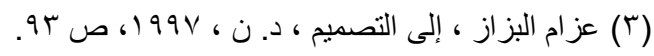

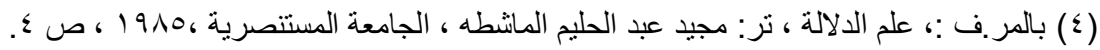

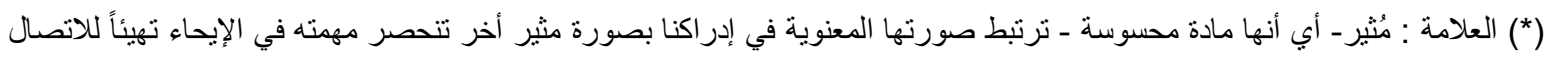

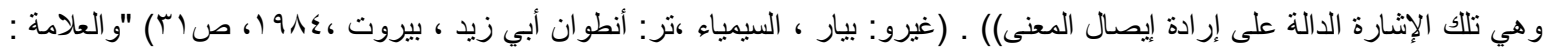

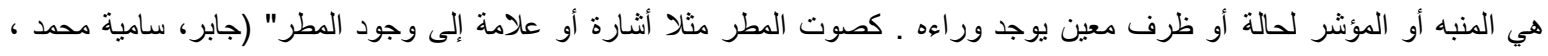

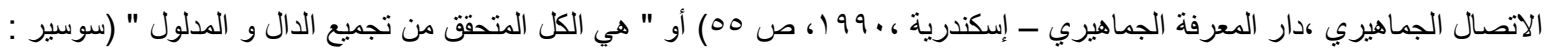

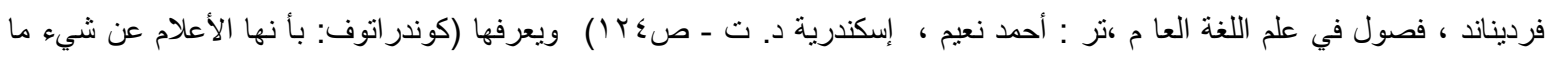
كالاخان يعتبر أثنارة طبيعية أو علامة على وجود النار (كندراتوف، الإشارات ، تر:الأصوات و الإشارات ، تر:شوقي جلال، الهيئة المصرية

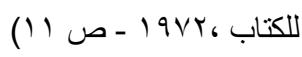

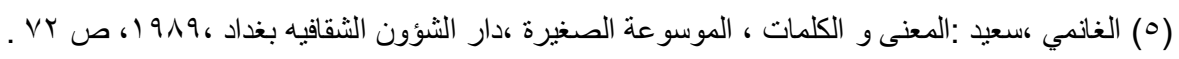

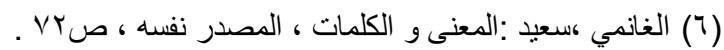

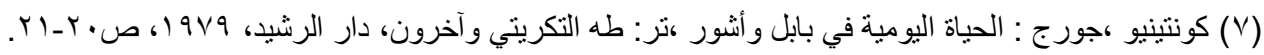

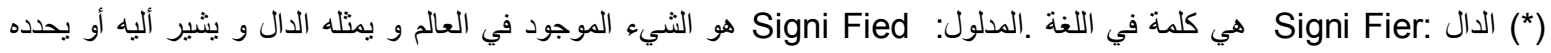

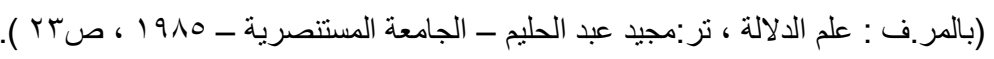

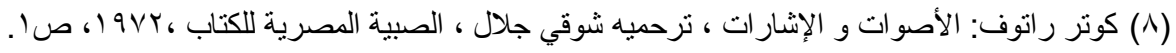

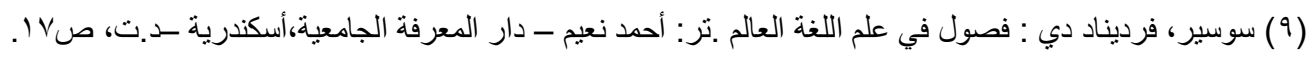

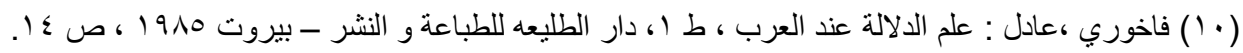

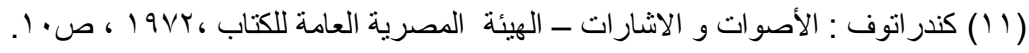

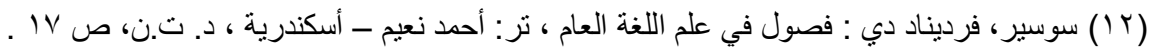

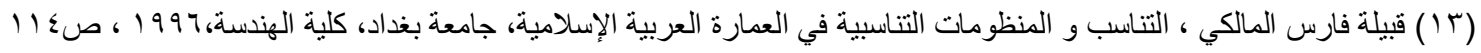

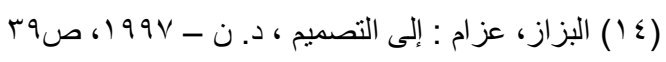

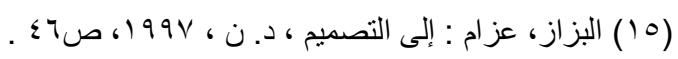

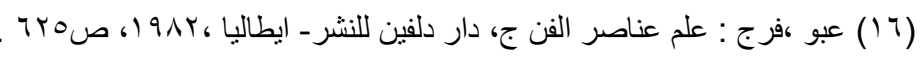

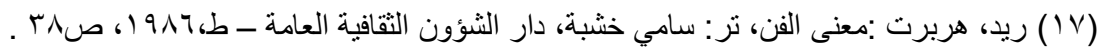




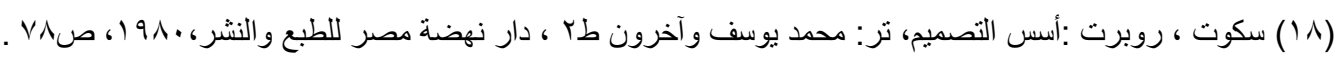

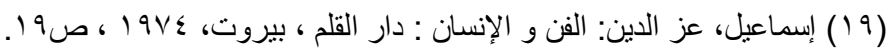

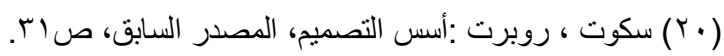

Francis D. K.Ching Newyork 1979 ,p119

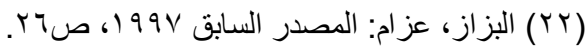

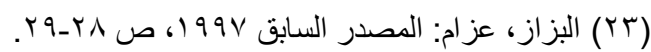

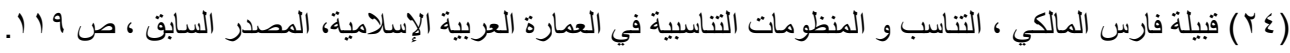

(ro)Francis D.K. ching 1979p72

Francis (YT)

(YV)

( $(\wedge)$ Francis D.K. ching,p86

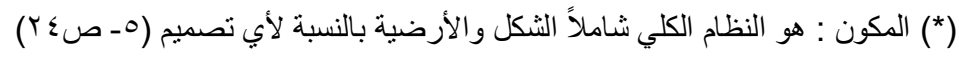

. r.Graves, Maitland, 1951 ( $(\uparrow)$

r. Graves , Maitland, 1951 (r·)

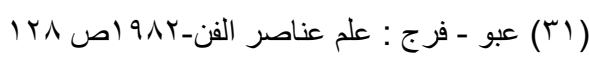

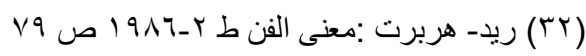

rrGraves, Maitland, 1951, p 201.

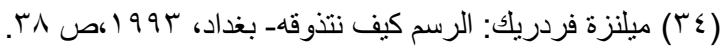

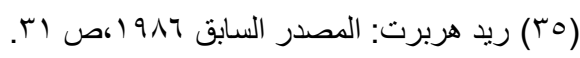

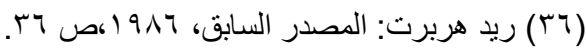

Graves (rv)

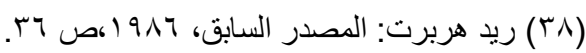

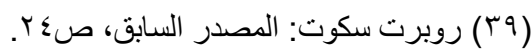

Graves ( ( • )

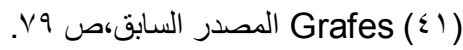

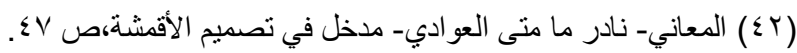

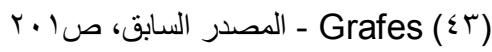

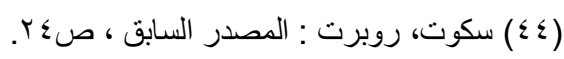

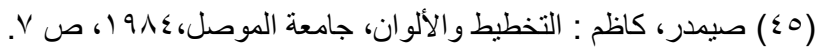

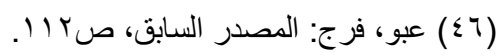

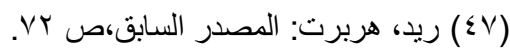

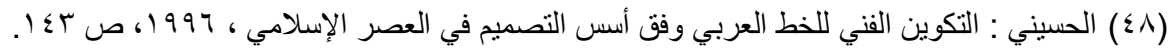

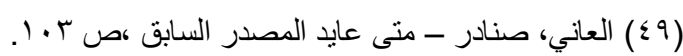

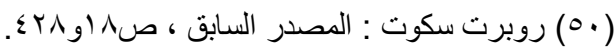

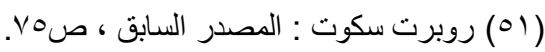

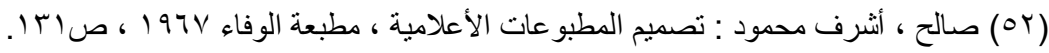

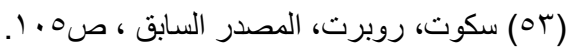

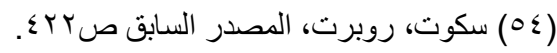

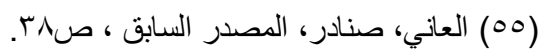

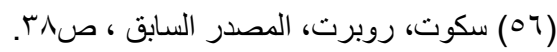

Graves, maitlind (ov) 


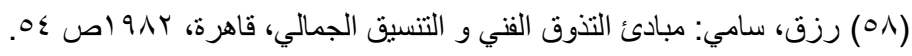

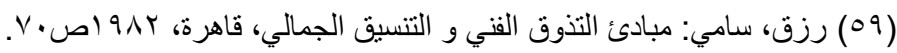

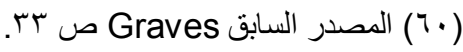

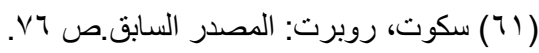

(**) الوظائفية: وهي مبدأ أن يكون للثيء موضع التصميم وظيفة في شكله وحجمه وطريقة استخدامه بحيث يسهل عليه أداء وظيفته التي صمم

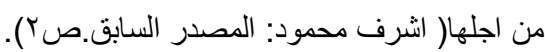

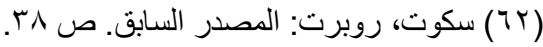

(זT) العاني، صناد: المصدر السابق ،ص

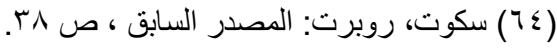

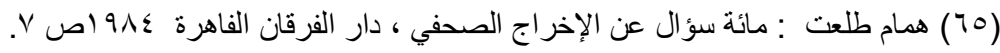

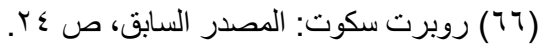

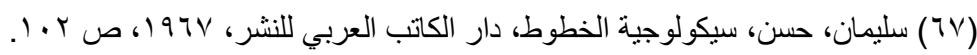

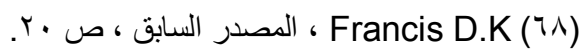

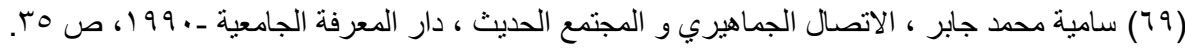

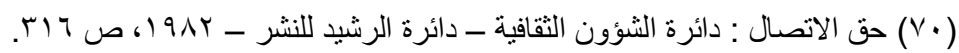

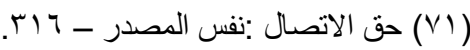

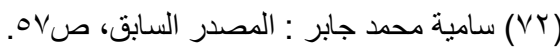

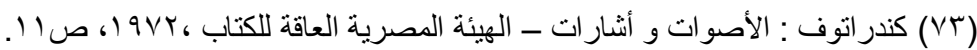

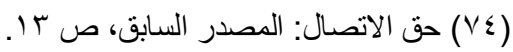

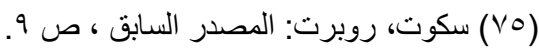

(VT)

(ادمن، ارون: الفنون و الإنسان ، دار النهضة العربية، (VV)

(V^)

(")

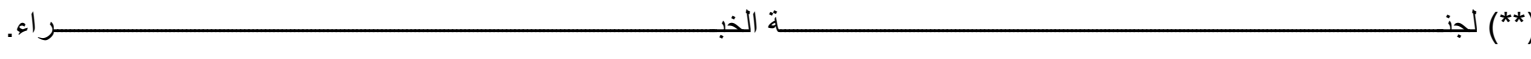

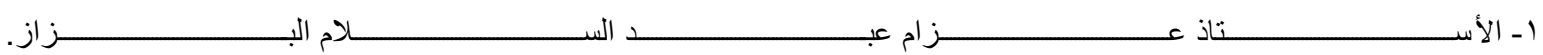

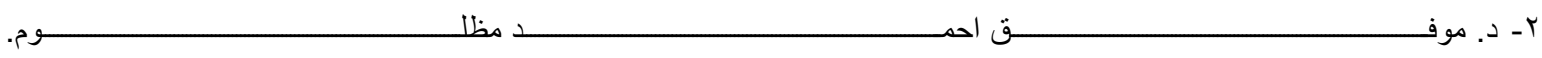

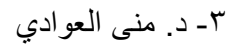

قائمة الاصادر

- أولا: المصادر العربية :

ا ـ المالكي، قبيلة فارس: التناسب و المنظومات التناسبية في العمارة الإسلامية ، كلية الهندسة ،أطروحة. دكتور اه غير منشورة ، جامعة بغداد ،

1997

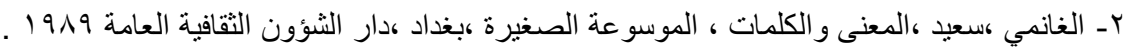

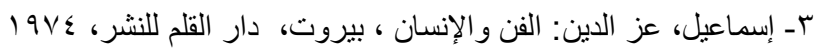

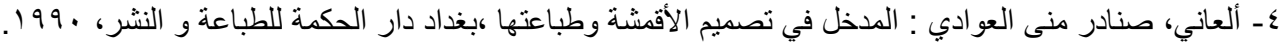

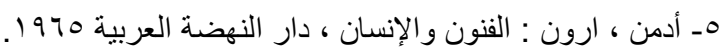
7- الحسني ،أياد:التكوين الفني الخط العربي وفق أسس التصميم في العصر الإسلامي،أطروحة دكتور اهن غير منشورة،كلية الفنون الجميلة ، جامعة بغداد ، 1997.

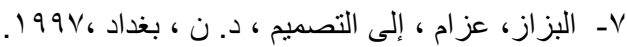

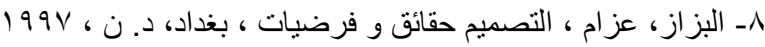


9- بالمر .ف :، علم الدلالة ، تر: مجيد عبد الحليم الماشطه ، الجامعة المستتصرية ،1900،

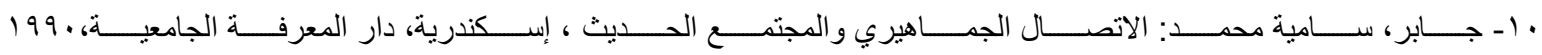
(بد

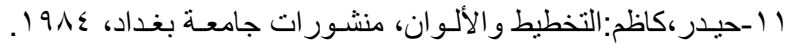

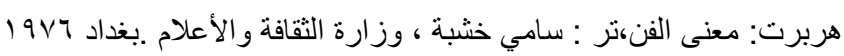

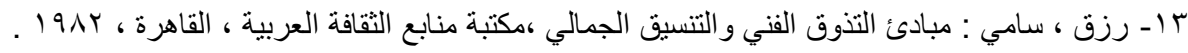

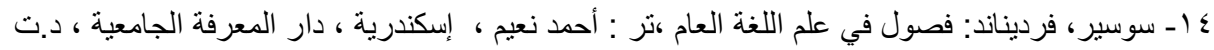

$-1 V$

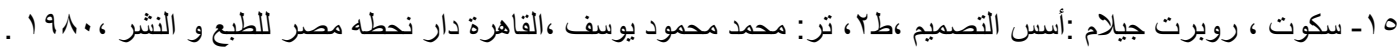

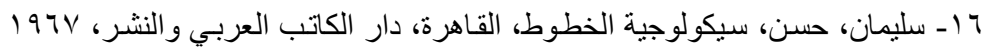

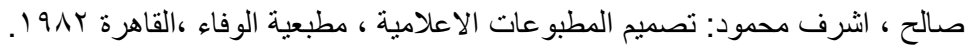

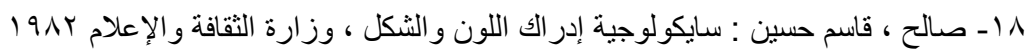

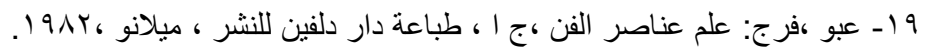

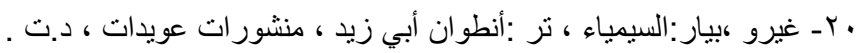

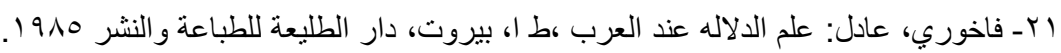

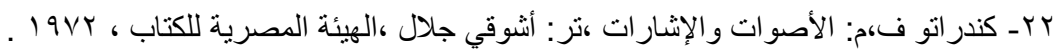

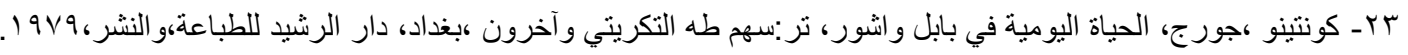

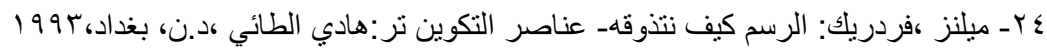

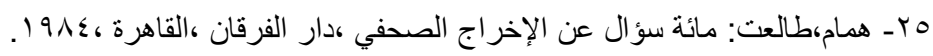
ثانيا: المصادر الأجنبية :

26- Francis D.K Ching :Architecture Form, Space Sorder,van Nostrand Reinhold Com. New York 1979.

27- Graves, Mai Tland :The Art Of Cclcy and Design, Mc- Graw, Hill Book com .. 2nd , ed. , New York, 1951. 